\title{
Change in occupational tasks and its implications: evidence from a task panel from 1973 to 2011 for Western Germany
}

\author{
Tobias Maier $^{1}$ (D)
}

Accepted: 3 May 2021 / Published online: 14 May 2021

(c) The Author(s) 2021

\begin{abstract}
The change of tasks in occupations is of interest to economic and sociological research from three perspectives. The task-based technological change approach describes tasks as the link between capital input and labor demand. In human capital theory, tasks are used to distinguish between general and specific human capital. Moreover, in institutional economics or sociology, it is argued that the specificity of occupations influences the marketability of the corresponding skills and tasks. However, data sources that illustrate task change within occupations are rare. The objective of this paper is therefore to introduce a task panel, which is created based on 16 cross-sectional surveys from between 1973 and 2011 of the German microcensus (Labor-Force-Survey), as an additional source to monitor task change. I present and discuss the harmonization method for eleven main activities that are exercised by the incumbents of the occupation within 176 occupational groups. To demonstrate the research potential of this novel data source, I develop an alternative theoretical view on the task-technology framework and classify the harmonized tasks according to their relationship to technological inventions in the third industrial (micro-electronic) revolution (technologically replaceable, technology-accompanying, technology-complementary and technologically neutral). Matching the task panel to an already existing Occupational Panel (OccPan) for Western Germany from 1976 to 2010, I can use fixed-effect regressions to show that changes of tasks within occupations correspond with theoretical expectations regarding the median wage growth of an occupation. The task panel can be matched to any data set containing a German classification of occupations from 1975, 1988 or 1992 to investigate further effects of task change on individual labor market success.
\end{abstract}

Keywords Fixed-effect regressions · Microcensus · Micro-electronic revolution · Occupational panel $\cdot$ Specificity of occupations $\cdot$ Task-biased-technological-change $\cdot$ Task panel $\cdot$ Wage growth

Tobias Maier

tobias.maier@bibb.de

1 Federal Institute for Vocational Education and Training, Robert-Schuman-Platz 3, 53175 Bonn, Germany 


\section{Introduction}

The search for reasons behind and consequences of a changing demand for tasks in the workplace over time has become more prominent in the research of economists and sociologists in recent years. However, data sources that illustrate task change over time are rare. The objective of this paper is therefore to introduce a task panel, which is created based on the German microcensus, the largest household survey in Germany, as an additional data source to monitor task change between 1973 and 2011. I will disclose how the task information in different survey years can be harmonized at an occupational level, discuss the attendant benefits and shortcomings, and demonstrate the research potential of the newly created task panel, which is openly accessible for academic research (https://doi.org/10. 7802/2126).

The invention of integrated circuits (1959) and microprocessors (1971) made it possible to replace hardware with software solutions. The impact of this technological change on labor demand has been widely discussed in economic and sociological literature (c.f. Chennells and Reenen 1999). Autor et al. (2003-ALM in the following) were the first to demonstrate that technological change in the third industrial or micro-electronic revolution did not purely substitute or complement the demand for labor with regard to a certain formal skill level (Acemoglu 1998; Goldin and Katz 1998). It interacted instead with the specific tasks carried out by workers (task-biased technological change, TBTC). In principle, any recurring task carried out according to clear rules has been at risk of substitution.

The (changing) relationship between tasks and technology over time is, however, not the only motivation for according further consideration to tasks that are exercised in the workplace. From a human capital perspective, the measurement of general and specific human capital and its transferability between jobs has a long history, especially in economic literature (Becker 1962). Newer literature shows that tasks performed in the workplace (Gathmann and Schönberg 2010; Nedelkoska et al. 2015; Ormiston 2014) or skills provided in training programs for the exercising of certain tasks (Eggenberger et al. 2018; Grønning et al. 2020) can provide a deeper insight into skill transferability than a pure classification by occupation (Kambourov and Manovskii 2009).

Furthermore, task profiles of occupations are also of research interest from an institutional point of view (Christoph et al. 2020). It is argued that the specificity of occupations influences the marketability of the corresponding skills and tasks (Rotolo and McPherson 2001). Whereas incumbents of occupations with a wide set of tasks can rely on a broader skill set, which offers them access to various jobs, occupational incumbents with specific skill sets can use their skills only in the corresponding niche occupations. However, narrow skill profiles facilitate the matching of persons to jobs (Dengler et al. 2016), because they send clear signals of the skills offered and tasks demanded. For example, Eggenberger et al. (2018) showed that persons who have been trained in specific occupations have higher economic returns to education but also longer search periods, whereas persons with more general skill profiles experience a higher occupational mobility (see also Geel and BackesGellner 2011). Stuth (2017) demonstrated the signaling value of task profiles by showing that workers with common sets of tasks or with a high variability of tasks are more likely to be employed in temporary employment, because their fit to a position offered is less clear than in an occupation with a narrow ranges of tasks.

While it is undisputed that tasks (or skills, which enable the performance of tasks) have a high explanatory power for wages, as well as for employment and career chances, only a few data sources capture the tasks performed in a workplace or within an 
occupation. Whereas research for the United States can rely on the Occupational Information Network $\left(\mathrm{O}^{*} \mathrm{Net}\right)$, European data sources are rare. Germany is one of the few countries with information on the development of tasks in the workplace over time. The employment surveys of the Federal Institute for Vocational Training and Training (BIBB) in cooperation with the Institute of Employment Research (IAB) in 1979, 1985/86, and 1991/1992 or the Federal Institute for Occupational Safety and Health (BAuA) in 1998/99, 2006 and 2012 measure a wide range of tasks over time. They are therefore often used to either analyze the effects of tasks and wages directly (Antonczyk et al. 2009; Spitz-Oener 2006) or to calculate skill profiles for occupations, which are then matched to panel data sets (Black and Spitz-Oener 2010; Gathmann and Schönberg 2010). Furthermore, the "Berufenet" is an online database of the German Federal Employment Agency which provides tasks information at a detailed occupational level (Dengler and Matthes 2018; Dengler et al. 2014). However, the available data sources come with a few pitfalls.

An expert database such as DOT, O*Net or for Germany Berufenet misses variations in job tasks among incumbents of the same occupation (Autor and Handel 2013; Matthes et al. 2014). They can, however, be used to disclose changes of occupational tasks over time at a detailed occupational level, if the database is saved for research purposes on a regular basis. Unfortunately for Germany, this has not been the case with the Berufenet before 2010 to my knowledge. The main criticism of the German BIBB/IAB and BIBB/ BAuA employment studies is that only occupation-specific task bundles of employed persons are captured, and these task bundles somehow unequally reflect the activities exercised in occupations (Christoph et al. 2020; Matthes et al. 2014). Due to this question design, the conceptual framework of ALM, which is mainly based on generic skills/tasks, cannot be a fit (Matthes et al. 2014). Furthermore, it must be noted that the amount and content of tasks items surveyed is not comparable between the different waves and thus not ideal for the measurement of task changes within occupations over time (RohrbachSchmidt and Tiemann 2013). To overcome this pitfall of the employment survey for analyzing the task-technology relationship Rohrbach-Schmidt and Tiemann (2013) therefore suggest relying on measurements of the employment surveys, which describe the characteristics of the workplace directly and consistently over time. This does not, however, help if the calculation of skill or task-profiles over time is of interest. The aim of this paper, therefore, is to present the German microcensus (Labor Force survey), as an additional data source to display task change between and within occupations between 1973 and 2011.

The microcensus is a one-percent sample of the German population and represents an official statistic for the structure of the population, its education and economic activity. At specific intervals (1973, 1976, 1978, 1980, 1982, 1985, 1987, 1989, 1991, 1993, 1995, 1996, 2000, 2004, 2007 and 2011) the microcensus collected information on the main activity carried out in an occupation. The predominant activity is not ideal for measuring the complexity of an occupation. However, due to the large sample size of the microcensus, it is a very good construct to measure severe changes in the occupational activities. The law of large numbers guarantees stable long-term results for the averages of random events. This means that if activity A is predominant and activity B only marginal for some occupational incumbents, the opposite situation may pertain in other cases. If one observes enough occupational incumbents, the distribution of predominant tasks among them should therefore provide a clear picture of the most relevant tasks in an occupation. The advantage of the microcensuses, in contrast to the employment surveys, is that task information is collected more often and, as I will show, can be harmonized over the survey years. This allows a better understanding of changing task profiles between and within occupations. 
Like the employment surveys, the tasks surveyed in the microcensus tend to be occupation-specific rather than generic and thus do not fit the conceptual framework of ALM perfectly. A consistent measurement of tasks over time is, however, of value as such and constitutes an improvement of the existing data-landscape for two reasons. Firstly, the relationship of the task bundles and technological innovations during the micro-electronic revolution can still be expressed via a modification of the ALM scheme. Secondly, the development of occupation-specific task profiles permits the expression of (dis)similiarity of occupations and thus gives an insight into the specificity and transferability of occupationspecific tasks over time.

I begin below by presenting the harmonization process of tasks between 1973 and 2011 (Sect. 2). In Sect. 3, I illustrate the development of tasks and occupations over time. Furthermore, I discuss the robustness of the results in the light of alternative assumptions and point out the strength and weaknesses of the data source and of the harmonization approach. Unfortunately, there is no external benchmark with which the task changes of the microcensus can be compared. However, I can check for plausibility from a content point of view, i.e. whether substantial patterns of task change accord with or contradict existing literature. To do this, I classify the activities exercised according to their relationship to a new technology during the period of the micro-electronic revolution. Thus, I develop an alternative theoretical view on the task frame developed by ALM in Sect. 4 and test it by matching the newly developed time series on tasks to an existing Occupational Panel (OccPan) for Western Germany in 1976 to 2010 (Hausmann et al. 2015b). My fixed effect regressions illustrate that changes of tasks within occupations correspond with theoretical expectations regarding the median wage growth in the occupation. Section 5 concludes and demonstrates the potential of the new time series on tasks.

\section{Creating an occupational panel on tasks}

I base my analyses on the Scientific Use Files (SUF) of the German microcensuses, which represents a $70 \%$ sub-sample of the survey. ${ }^{1}$ However, even in the SUF, the sample size per survey year is quite large (minimum of 169,189 respondents in 1973). The microcensus questions are created on the basis of the Microcensus Law, which is renewed on a timelimited basis. On the one hand, this means that the answer to most of the questions is obligatory, which results in a very high response rate. On the other hand, it means that certain variables are only available in some years, and even if the same information is collected in several years, it is still possible for the wording of the question to change over time. Lengerer et al. (2012) describe the harmonization process of the microcensus cross sections from 1962 to 2006 . As I adhere to the recommendations given by the authors, I will only briefly state which variables I focus on to harmonize the cross sections.

I only concentrate on persons who work at least one hour per week and live in Western Germany. ${ }^{2}$ I exclude soldiers, persons performing community service and persons in collective accommodation, as well as persons with incomplete values for their occupation

\footnotetext{
1 The survey years from 1982 onwards are also available as a full sample in on-site use of the Research Data Centre of the Statistical Offices of the Länder. I chose the SUFs so as to have a longer time series.

${ }^{2}$ From 1991 onwards, the state of Berlin as a whole is considered as part of Western Germany.
} 
or workplace tasks. ${ }^{3}$ Apart from restricting every survey year to the same population, I additionally harmonize standard information about sex, age, working hours, ${ }^{4}$ nationality (German or non-German), occupational status, ${ }^{5}$ sector (primary, secondary, tertiary) and occupational degree (see Table 3 in the "Appendix") of the respondents.

To calculate occupation-specific task profiles, the harmonization of the occupational information is crucial. In the survey years from 1973 to 1991, the occupations are classified at a three-digit level (occupational groups) according to the national classification of occupations of 1975 (KldB75), whereas in the survey years from 1993 to 2011, occupations are classified according to the national classification of occupations of 1992 (KldB92). To create a homogenous occupational classification, I aggregate both classifications according to the smallest common denominator. Here, I follow the transformation scheme as shown in Schimpl-Neimanns (2003). To increase the usability of the occupational panel, I also code the occupational information into the national classification of occupations of 1988 (KldB88), which is quite similar to the KldB92 and is used in other data sources (see Sect. 4.4). After grouping all occupational categories of the different occupational classifications into unambiguous categories, I combined occupational categories with small sample sizes $(\mathrm{n}<30)$ with occupational categories with a similar task focus (Tiemann et al. 2008). ${ }^{6}$ The occupations "unpaid family workers (not agriculture)", "apprentices, interns without a fixed future career path" and "other workers without further specified tasks" are excluded. These steps result in 176 newly constructed harmonized occupational groups.

In the survey years 1973, 1976, 1978, 1980, 1982, 1985, 1987, 1989, 1991, 1993, 1995, 1996, 2000, 2004, 2007 and 2011, respondents are asked about the activity they predominantly exercise. However, the response values provided and corresponding wording change over time. We can identify three different periods of task collection. In the cross sections from 1973 to 1980, ten task items could be selected that mainly concentrated on production tasks (Table 4 in the "Appendix"). However, additional information on those task items in four categories ("task focus","object of work", "main field of function/operational area", "main services"), with up to ten additional items per category, was also requested (Table 5 in the "Appendix"). In the years from 1982 to 1995, the content of the items changed compared to 1973 to 1980, but remained stable for those 13 years. In the survey years 1996 to 2011 , there were twice as many task items collected as in the prior periods (Table 6 in the

\footnotetext{
3 Due to the mandatory reply, the share of missing information in the occupation and/or never exceeds $2.4 \%$ in a survey year.

4 This is the usual working time in a week.

5 The occupational status can be merged to eight harmonized categories ("self-employed, without employees", "self-employed, with employees", "helping family members", "public servants/judges/policemen", "white-collar worker", "blue-collar worker/homeworker", "commercial and technical apprentices" and "industrial apprentices").

6 The following 21 occupations have been grouped: occupations specialized in metal sheet (211), wire (212) and metals (213) to (210) occupations in non-cutting metal forming processes; occupations in the production of confectionary goods and ice cream (433) with (392) pastry cooks; house and business servants (794) with assistants (531); surveying and mapping engineers (604) with technicians (624); railway operation personnel (712) with other vehicle operation staff (713); stevedores, movers (743) with warehouse and transportation workers (744); officials, ministers (761) with association presidents, functionaries (763); security inspectors (803) with health protection occupations (805); judicial officers (812) with legal advisors (813) and occupations in textile cleaning (932) with occupations in textile care (931). Obviously aging ((80) "stone cutters and processors" and (286) "clockmakers", (360) "textile finishers") and emerging occupations ((882) "other humanities and educational scientists") had only a small sample size in the very end and beginning of the time series respectively. Here, I aggregated the observations of the years affected with the previous and following survey year before calculating the task shares within the occupation.
} 
"Appendix"). The increase can mainly be traced back to a more precise listing of service tasks. If, however, it is assumed that intra-occupational task changes are relatively stable between two successive survey years, we can calculate transition keys between the three different periods of task measurement in the microcensus. The guiding principle is, as in the harmonization of the occupational classification, the principle of the smallest common denominator, which requires a conversion into the task items collected in the survey years between 1982 and 1995. I therefore calculate transition probabilities to convert the task measurement $T_{j}$ from 1996 to 2011 , and $T_{k}$, from 1973 to 1980 , to the task measurement $T_{i}$ between 1982 to 1995, for each KldB88h. In the following, I describe the generation of the transition key for the survey years 1995 and 1996. The aim is to obtain transition probabilities from the 20 tasks $T 96_{j}$ measured in 1996 to the ten tasks $T 96_{i}$ measured in 1995.

For easier handling of the data, I first group the 20 tasks in 1996 to ten tasks $T 96_{j} j=1$, ..., 10) with regard to the apparent, measured content (see Table 7 in the "Appendix"). Within each harmonized occupation KldB88h, we now calculate the share of persons who carry out a certain task in the survey year 1996:

$$
T S 96_{j}=T 96_{j} / \sum_{j=1}^{10} T 96_{j} \quad \text { with } j=1, \ldots, 10
$$

and in the survey year 1995:

$$
T S 95_{i}=T 95_{i} / \sum_{i=1}^{10} T 95_{i} \quad \text { with } i=1, \ldots, 10 .
$$

The information on the task exercised is measured on a nominal scale. The assigned values $i=1, \ldots, 10$ and $j=1, \ldots, 10$ have no ordinal meaning. Thus, the order of the tasks is not significant. For more convenient programming, $T S 96_{j}$ and $T S 96_{i}$ are therefore both sorted in descending order. To avoid misunderstandings, the task shares $T S 96_{r}$ are indicated with $\mathrm{r}=1, \ldots, 10$ for the corresponding rank, where $T S 96_{r}=\max _{j=1}^{10} T S 96_{j}$ for $\mathrm{r}=1$.

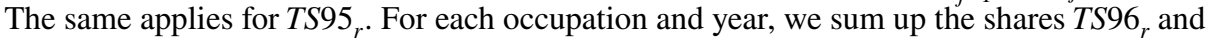
$T S 95_{r}$ to a discrete cumulative distribution function $F$ of tasks shares within occupations:

$$
\begin{aligned}
& F(\text { TS96r })=\sum_{n=1}^{r} p\left(\text { TS96 }_{n}\right) \\
& F(T S 95 r)=\sum_{n=1}^{r} p\left(\text { TS95 }_{n}\right) .
\end{aligned}
$$

The share $p$ is interpreted as probability. For each occupation, we now have a cumulative distribution function of tasks based on the persons exercising this certain occupation. If the assumption is true that the actual exhibited activities within each occupation remain the same in 1995 and 1996, the differences in the distribution of $F\left(T S 96_{r}\right)$ and $F\left(T S 95_{r}\right)$ would solely be caused by different measurement of those activities due to different wordings in the corresponding microcensus questionnaires. To infer from the distribution of 1996 to that of 1995 , we therefore just have to oppose $F\left(T S 96_{r}\right)$ to $F\left(T S 95_{r}\right)$ and then transform $T 96_{j}$ to the corresponding $\widehat{T 96}_{i}$ for each $r$ until we obtain a new cumulative distribution function $F\left(\widehat{T S 96_{r}}=F\left(T S 95_{r}\right)\right.$. Hence, the procedure assumes that the highest task share in $1996\left(\right.$ TS $_{r}$; with $\left.r=1\right)$ corresponds to the highest task share in $1995\left({\text { TS } 95_{r} \text {; }}^{\circ}\right.$ 
with $r=1)$, the second highest task share $(r=2)$ in 1996 to the second highest $(r=2)$ in 1995 and so on. To obtain new shares of tasks $\widehat{T S 96_{r}}=T S 95_{r}$ and a new distribution of tasks $F\left(\widehat{T S 96_{r}}\right)$ within occupations for the survey year 1996, the procedure can generally be described as follows.

$$
\widehat{T S 96}_{r} \begin{cases}T S 96_{r}-\left(T S 96_{r}-T S 95_{r}\right) & \text { if } F\left(T S 96_{r}\right)>F\left(T S 95_{r}\right) \\ T S 96_{r} & \text { if } F\left(T S 96_{r}\right)=F\left(T S 95_{r}\right) \\ T_{S 96_{r}+\left(T S 96_{r+1}-T S 95_{r+1}\right)} \text { if } F\left(T S 96_{r}\right)<F\left(T S 95_{r}\right)\end{cases}
$$

For example, if $F\left(T S 96_{1}>F\left(T S 95_{1}\right)\right.$, the overlap $\left(T S 96_{1}-T S 95_{1}\right)$, has to be attributed to $\widehat{T S 96_{2}}$; if $F\left(T S 96_{1}<F\left(T S 95_{1}\right)\right.$, the remaining gap $\left(T S 95_{1}-T S 96_{1}\right)$, in $\widehat{T S 96_{1}}$ has to be closed by the overlap of $T S 96_{2}-T S 95_{2}$. However, it is possible that the transformation of $T S 96_{r}$ to $\widehat{T S 96_{r}}$ needs more steps than formulated in Eq. (5). The adjustment algorithm therefore continues if $\widehat{F(T S 96)} \neq F($ TS95) until $\widehat{F(T S 96)}=F(T S 95)$ :

$$
\widehat{T S 96}_{r}\left\{\begin{array}{ll}
\widehat{T S 96}_{r}-\left(\widehat{T S 96}_{r}-T S 95_{r}\right) & \text { if } F\left(\widehat{T S 96}_{r}\right)>F\left(T S 95_{r}\right) \\
\widehat{T S 96}_{r}+\left(\widehat{T S 96}_{r+1}-T S 95_{r+1}\right) & \text { if } F\left(\widehat{T S 96}_{r}\right)<F\left(T S 95_{r}\right)
\end{array} .\right.
$$

Once $\widehat{F(T S 96)}$ corresponds to $F(T S 95)$ in each occupation, we can calculate the frequency distribution $T S 96_{j i}$ from each $T S 96_{j}$ to each $T S 96_{i}$. We simply need to apply the occupation-specific distribution matrix $D$ from $r$ to $i$ in 1995 (determined by calculating $T S 96_{r}$ from $T S 96_{i}$ ) to obtain $\widehat{T S 96}_{i}$. out of $\widehat{T S 96}_{r}$. We can now express $\widehat{T S 96}_{j i}$ as a discrete cumulative distribution function:

$$
F\left(T S 96_{i}\right)=\sum_{i=1}^{10} p\left(T S 96_{i j}\right) .
$$

$F\left(T S 96_{j}\right)$ serves as a transition key from the task measured in 1996 to the task measured in 1995, based on the shares of persons who exercise a certain occupation. We therefore match $F\left(T S 96_{j}\right)$ to the occupation and task information of the surveys in 1996 to 2011 at an individual level and interpret this as a probability distribution. Every individual in the microcensus surveys from 1996 to 2011 is assigned a randomly drawn number between 0.0000001 and 0.9999999 . Based on this random number and on the according probability distribution $F\left(T S 96_{j}\right)$, each individual is assigned to a task $i$. To avoid any implausible assignment due to randomization, I repeat the process ten times by drawing ten different random distributions and assigning ten task values $i$ on the basis of the probability distribution. The final distribution of harmonized task shares within occupations is then generated by pooling the ten different task distributions.

For simplicity, the procedure for generating the transition key for a harmonized task series has been described for the two survey years 1995 and 1996 at occupational group level. Since the assignment takes place based on the rankings of the activities, the quality of the assignment depends on the unambiguity, meaning the steepness, of the task distribution. For the actual transition key, the harmonized occupations have therefore been further divided into sub-groups. I considered all work-related information such as occupational status, sector information, ISCED (Table 3 in the "Appendix") and the number of hours 
worked. ${ }^{7}$ The deeper disaggregation results in fewer persons per sub-group, and this leads to a steeper distribution of tasks but also to a low number of cases. As the key can only be applied for sub-groups that exist in each survey year, it is first calculated for all possible sub-groups and then aggregated step by step. Consequently, the transition key is first applied to all sub-groups. Observations that could not be matched are then matched to a transition key with fewer restrictions. ${ }^{8}$ Whereas the transition key is applied at the worker level, the final task distribution is obtained by weighting the harmonized predominant task of each worker with the number of hours worked. This ensures that persons in marginal employment are not weighted equally to full-time employees.

Table 1 provides examples of how the transformation process works from $T S 96_{r}$ to $\widehat{\text { SS96 }_{r}}$ for three selected occupational groups at aggregate level. The second column in Table 1 represents the predominant activities most frequently exercised within the occupational group in the microcensus 1995, where ten task categories are differentiated. The third column contains the most frequent tasks in the year 1996 according to 20 task categories. The 20 task categories are aggregated to ten task categories TS96 $r$ according to the rule in Table 4 in the "Appendix". The most frequent shares of TS96 $r$ are shown in the fourth column. In the case of "florists", for example, "planting, breeding, nourishing, harvesting, fishing" and "producing, processing, building/finishing, installing" has been combined to "planting, extraction, manufacturing". The distribution of the harmonized $\widehat{\text { TS } 6_{r}}$ can be seen in the fifth column of Table 1. The distribution of $\widehat{T S 96_{r}}$ resembles the distribution of $T S 95_{r}$, but differs due to a different composition of the occupation incumbents by occupational status, ISCED, sector, nationality and region. For all following years, the harmonized task distribution will also be affected by a change in the original 20 task categories, because they are linked via the distribution matrix D from TS96, to $\widehat{T S 96_{r}}$.

The same procedure as for the survey years 1995 to 1996 is applied for 1980 to 1982 to generate a transition key for the previous survey years. As the wording of the response categories in 1982 differs slightly compared to the other surveys in the 1980s, I replaced the occupation-specific task share in 1982 with a weighted average of the survey years 1982 and $1985 .{ }^{9}$ The transition key between 1980 and 1982 is thus a transition key between 1982/1985 and 1980. The decision favors a more consistent time series of activities while accepting a possible underestimation of the change of tasks within occupations.

As the activities "educating, teaching, training; supporting and advising; nursing/caring, treating medically or cosmetically; publishing, entertaining, presenting, informing" are relatively broadly defined (see Tables 4, 5 and 6 in the "Appendix"), I define them as "nursing/treating medically or cosmetically" if they occur in health occupations. ${ }^{10}$ For all other

\footnotetext{
7 Strictly speaking, the formal education level of the workers is not a workplace characteristic. However, in the absence of other information, it is the best guess for the required skill level. The working hours are considered as a categorical variable in $10-\mathrm{h}$ steps until $50 \mathrm{~h}$ and more.

8 The sub-categories were prioritized according to the following groups in descending order of priority: occupational status, sector, ISCED, hours worked and public sector.

9 The observations of 1985 are double-weighted.

${ }^{10}$ I consider the following 17 occupations: (303) "dental technicians", (304) "opticians", (684) "druggists, sales assistants in health food shops (Reformhaus)", (685) "assistant pharmacists" (841) "medical doctors", (842) "dentists", (843) "veterinarians", (844) “dispensing chemists", (851) "Healers, masseuses, balneotherapists, therapeutic occupations", (853) "nurses, midwives", (854) "nursing assistants", (855) "dieticians, nutrition professionals, pharmaceutical-technical assistants", (856) "receptionists in medical practices", (857) "medical-technical assistants", (861) "social workers, social care workers", (901) "hairdressers", and (902) "cosmeticians".
} 


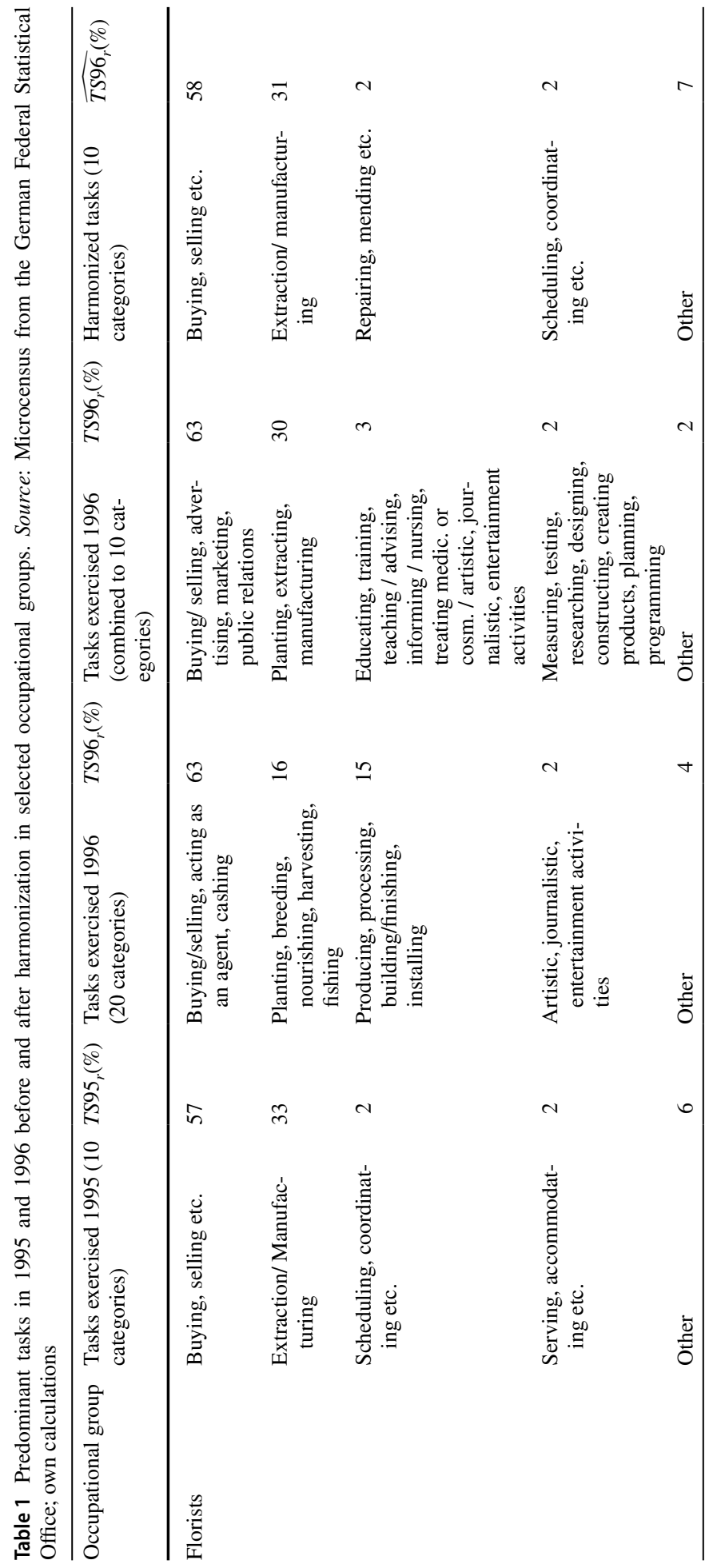




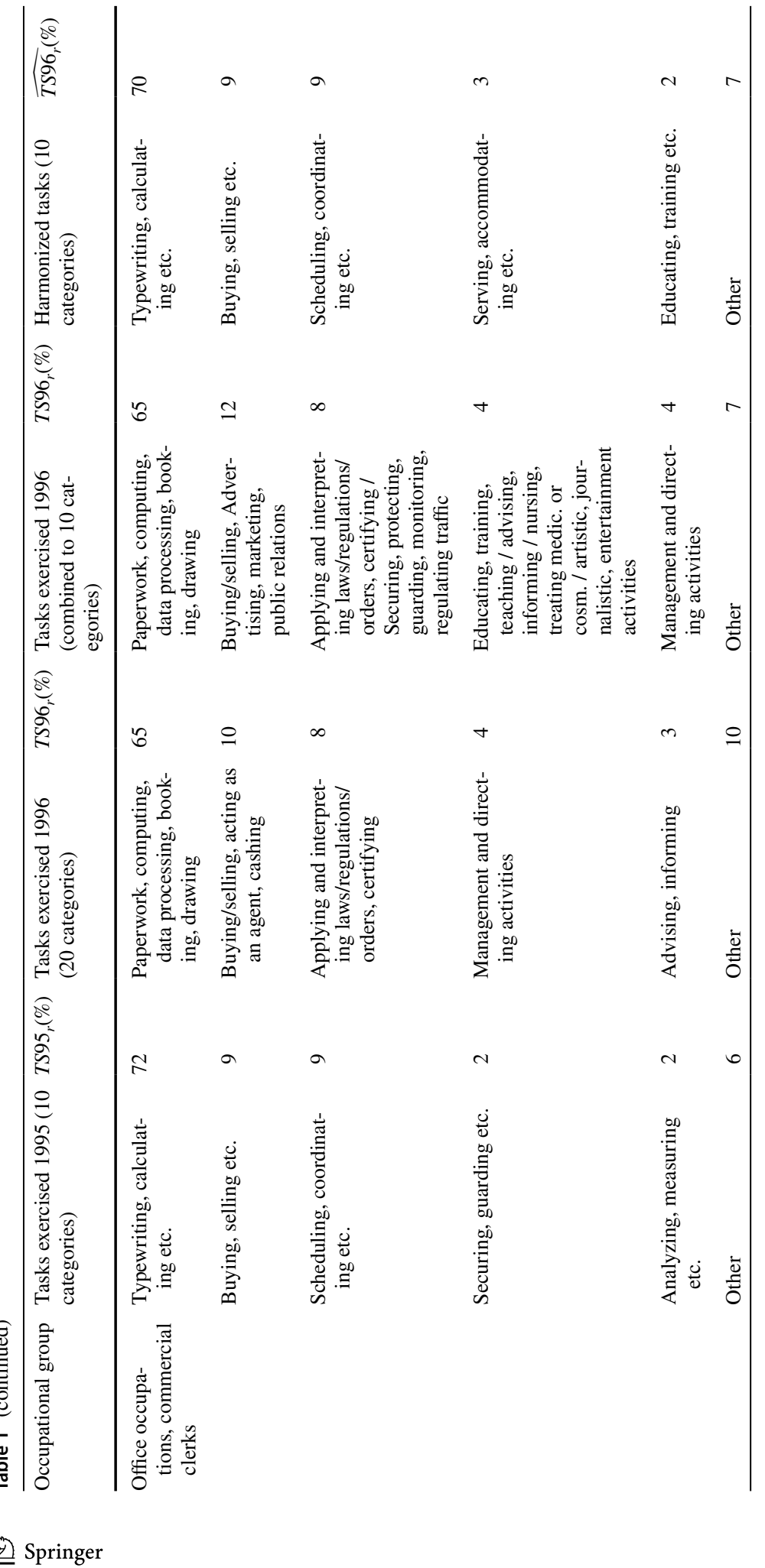




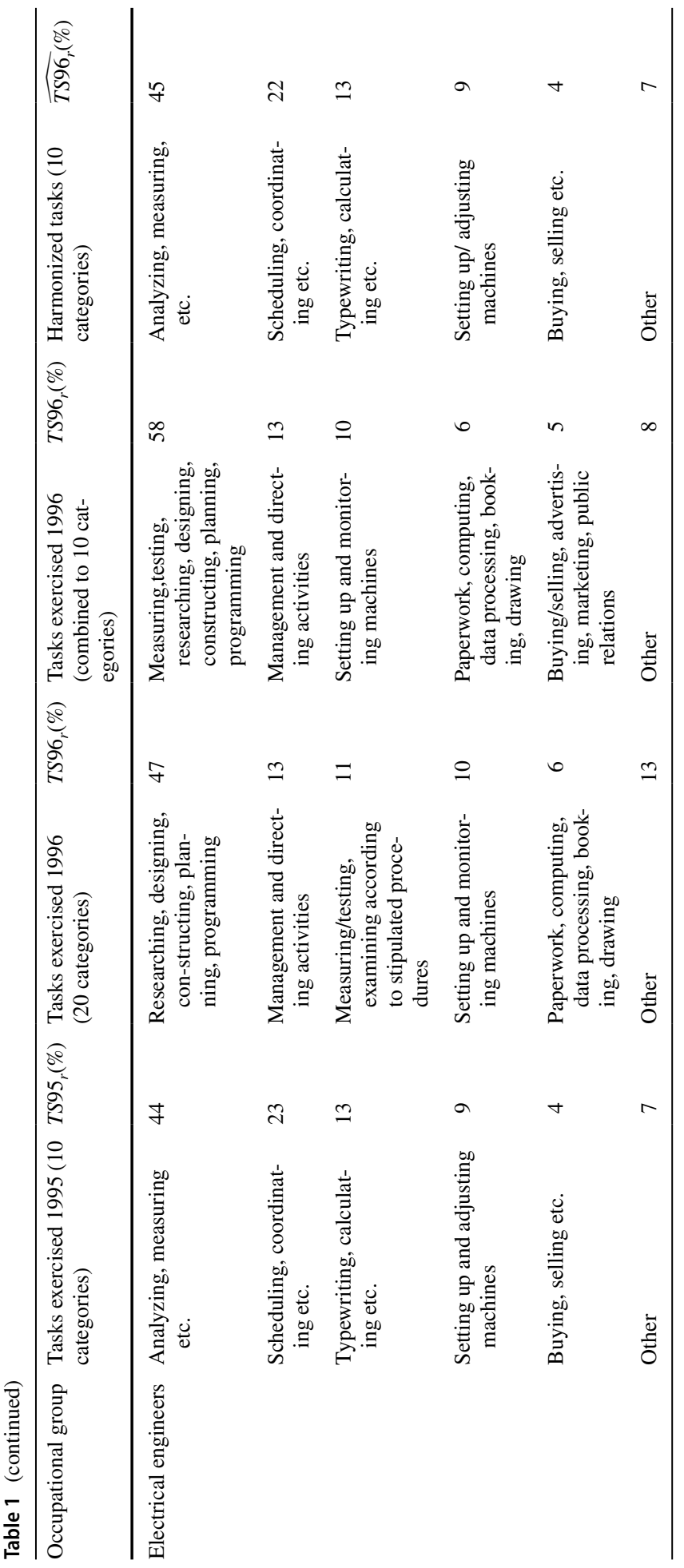


occupations it is assumed that the activity is "educating, training etc.". In the end, eleven tasks are differentiated.

\section{Panel results}

\subsection{Description}

Figure 1 provides an overview of the changing task shares $T S_{i}$ between 1973 and 2011 for Western Germany. Tasks involving "extraction/manufacturing" decreased dramatically from $29.5 \%$ in 1973 to $12.7 \%$ in 2011 . A sharply increasing task share can be found in activities that involve "educating, training etc." (from $4.2 \%$ in 1973 to $9.9 \%$ in 2011) and "nursing/treating medically or cosmetically" (from $2.6 \%$ in 1973 to $7.9 \%$ in 2011). "Typewriting, calculating" increases from $12.9 \%$ in 1973 to $17.1 \%$ in 1996, before falling to $15.7 \%$ in 2011.

The decline of "extraction/manufacturing" is, on the one hand, due to lower demand for occupations with a main focus on these activities. On the other hand, the task share also declines within the corresponding 176 occupational groups. This can be demonstrated on the basis of a shift-share analysis, which assumes for all practitioners that the tasks are distributed within the occupations (KldB88h) as in 2011. Figure 2 shows the differences between the actual development of task shares as shown in Fig. 1 and the development under the assumption of fixed task shares within occupations based on the survey
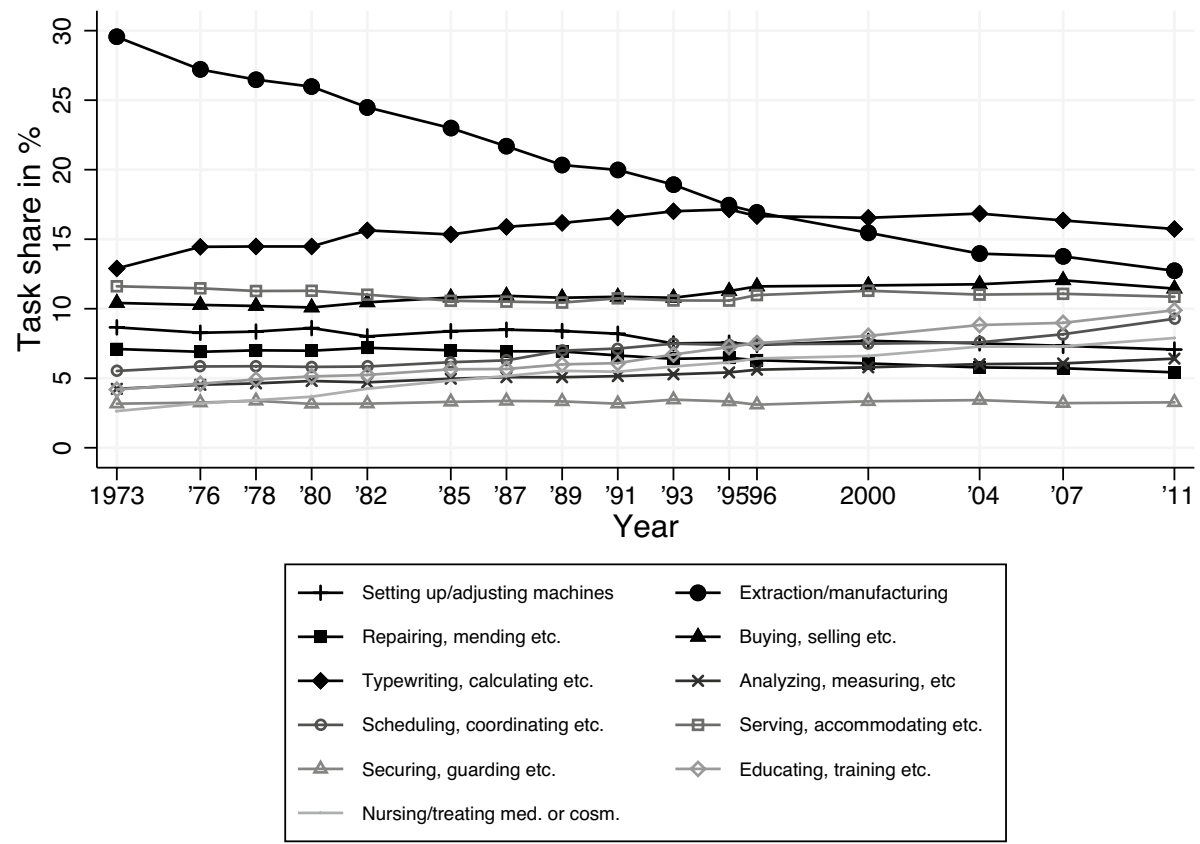

Fig. 1 Changing task shares in Western Germany from 1973 to 2011. Source: Microcensus from the German Federal Statistical Office; own calculations 

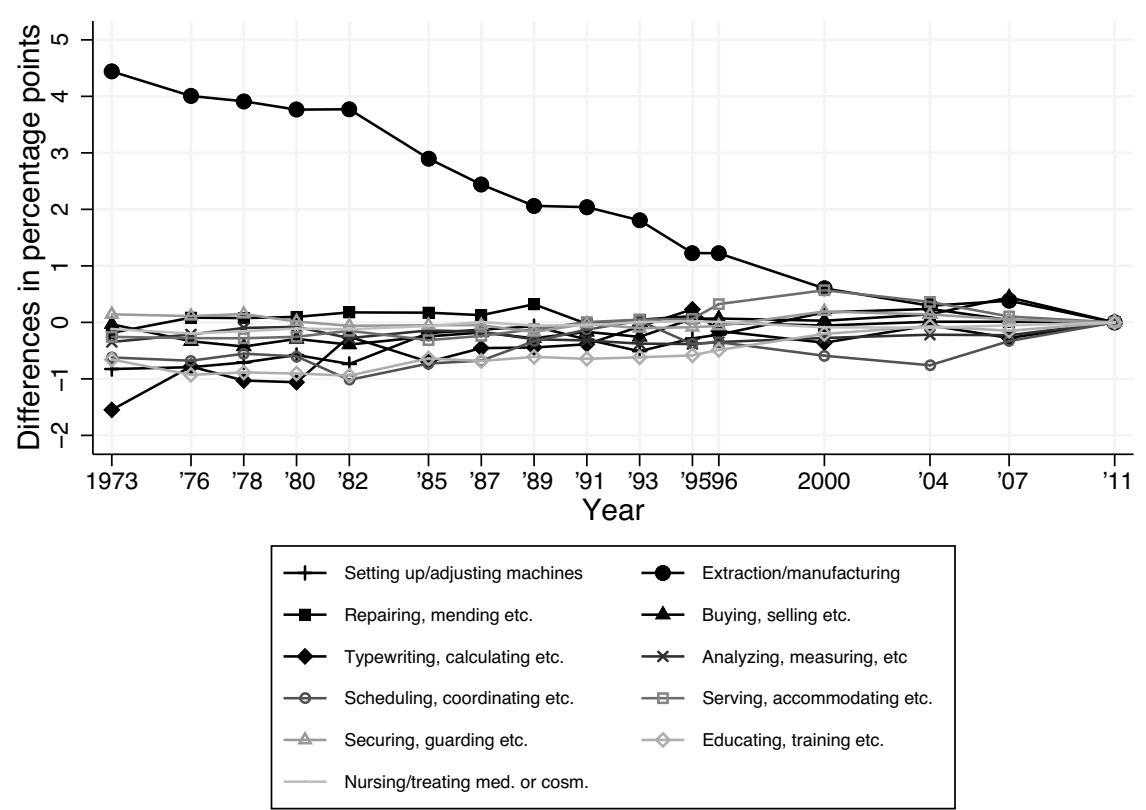

Fig. 2 Task change within occupations from 1973 to 2011 in Western Germany: Actual development compared to fixed task shares as in 2011 (shift-share). Source: Microcensus from the German Federal Statistical Office; own calculations

year 2011. As we can see, around 4.4 percentage points of the 16.8 percentage points decrease in the share of employment between 1973 and 2011 can be attributed to a decline in "extraction/manufacturing" within the occupational groups. This represents about $26 \%$ $(=4.4 / 16.8)$ of the total decline. For "educating, training etc.", around $16 \%$ (0.94 percentage points) of the increasing demand can also be ascertained within occupational groups. For "typewriting, calculation etc.", more than half of the increase in the predominant activity until the mid-1990s happened within occupational groups, and the small decline in tasks shares after that time can almost fully be attributed to a relative decline of the respective occupational groups.

\subsection{Robustness checks}

On the one hand, the task change shown over time depends on the assumption made for the harmonization, and on the other hand on the adequacy to reflect task change with only a few predominant activities. To demonstrate the impact of the assumptions, I repeat the task estimation with different sets of assumptions. It turns out that the order of the variables by which the transition key is built has no major effect on the result. The share of each task does not differ by more than 0.1 percentage points. The same is the case if we consider sex or age in the transition key. The results also differ only marginally (maximum of 0.3 percentage points) from the ones presented. As the selection pattern into workplaces by age 
and sex might also change over time, I decided not to include those variables in the transition key and to concentrate on those variables that are strictly workplace related.

The weighting of the task distribution by the hours worked has a larger impact on the result, even though the pattern remains the same. If the task distribution is not weighted by hours (and therefore assumes an equal working time of occupation incumbents), the share of "extraction/manufacturing" tasks is at 28.2\% (vs. 29.6\%) in 1973 and decreases by 16.5 percentage points to $11.7 \%$ (vs. $12.7 \%$ ) in $2011.27 \%$ of the declining task share (4.6 percentage points) takes place within the occupational groups. "Typewriting, calculationg etc." increases from $13.6 \%$ (vs. $12.9 \%$ ) to $18.6 \%$ (vs. 17.1\%) and falls to 16.7 (vs. 15.7\%) in 2011 . Only $40 \%$ of the increase until the mid-1990s is attributed to an increase within occupational groups. This shows that "extraction/manufacturing" tasks are more likely to be exercised in jobs with more working hours and that the decline of this predominant activity within an occupation tends to be observed in jobs with working hours below the average of the occupation. By way of contrast, "typewriting, calculationg etc." jobs are more likely to be exercised in jobs with shorter working hours, and the increase within an occupation was also observed in jobs with working hours below the occupational average. This effect can also be observed if persons with fewer than ten working hours a week are excluded from the calculation. ${ }^{11}$ Considering different working times seems more accurate than assuming equal working hours, I decided to prepare the results using working hours.

The task changes presented only reflect a shift in the composition of predominant activities. Peripheral changes of occupation-specific workplaces due to emerging or disappearing marginal activities are not considered. Even though Gathmann and Schönberg (2010) use the employment surveys to demonstrate that the picture of all tasks exercised and mainly exercised is quite similar, there might be a tendency to underestimate task changes within occupations. However, it must be noted that the differentiation by 176 occupational groups is more detailed than in previous studies based on the employment surveys (e.g. 64 occupations in Gathmann and Schönberg (2010) or 156 in Spitz-Oener (2006)).

To demonstrate the effect caused by an aggregation of the original predominant activities in eleven harmonized tasks, I compared the distribution of the original and harmonized tasks among occupations. For this purpose, I replicated the measures of "uniqueness/commonness" and "variety" as described in Stuth (2017). He used the 20 predominant activities of the German microcensus to analyze whether the uniqueness/commonness or variety of an occupation has an effect on the probability of being employed on a temporary contract.

The uniqueness or Commonness $s_{o}$ of an occupation $o$ is calculated using the index of qualitative variation. The empirical distribution of individuals $n$ with task $x$ over all nominal categories $s$ (number of occupations) is compared with the maximum dispersion that is theoretically possible [Eq. 8, see also Stuth (2017)]:

$$
\text { Commonness }_{o}=\sum_{x=1}^{11} \frac{s *\left(n_{x}^{2}-\left(\sum_{r=1}^{s} x_{r}^{2}\right)\right)}{n_{x}^{2} *(s-1)} * \operatorname{weight}\left(o_{x}\right) .
$$

The weight $\left(o_{x}\right)=\frac{N\left(o_{x}\right)}{\sum_{x=1}^{11} N\left(o_{x}\right)}$ is based on the frequency with which incumbents of the occupation $N\left(o_{x}\right)$ report performing the corresponding task. The measure of the commonness

\footnotetext{
11 In $2011,6.1 \%$ of the employed persons worked up to ten hours a week. In 1973, the share was only at $1.8 \%$.
} 
should range between 0 (unique set of tasks) and 1 (very common set of tasks). The measure Variety $_{o}$ of an occupation indicates the dispersion of individuals $n_{o}$ over all nominal categories $\mathrm{s}$ (here tasks) within each occupation compared to the maximum possible distribution (Eq. 9).

$$
\text { Variety }_{o}=\frac{s *\left(n_{o}^{2}-\left(\sum_{r=1}^{s} o_{r}^{2}\right)\right)}{n_{o}^{2} *(s-1)}
$$

If Variety $_{o}$ is close to 1, the occupation contains a rather broad set of predominant activities. Incumbents of occupations with a variety close to 0 perform a narrow set of tasks. Both indicators are calculated separately for each survey year.

The results show that the harmonization affects the commonness but not the variety of an occupation. On average over all occupations and years, the median of the commonness with the harmonized tasks is 0.92 (std. dev. $=0.05)^{12}$ if measured with 11 and 0.87 (std. dev. $=0.07)$ if measured with the original tasks. Due to fewer categories, there are more occupations with a common set of tasks if the harmonized tasks are used.The correlation of the two uniqueness measures for the years 1996 to 2011 is 0.47 .

For the variety of tasks within occupations, there are no striking differences between a calculation of the task measure according to the 11 harmonized or the 20 original tasks. The correlation between both measures in all years is 0.88 . For all survey years, the median of Variety $_{o}=0.55$ (std. $\left.=0.20\right){ }^{13}$

Unfortunately, there is no external benchmark with which the task changes within occupations of the microcensus can be compared. The employment surveys are more detailed, but the wording of the tasks differs from the wording in the microcensus and they vary in the measurement over time (see Sect. 1). No assurance can therefore be provided with regard to whether differences in task trends are due to a rather "rough" but constant measurement of tasks in the microcensus or caused by a more detailed but rather inconsistent measurement in the employment surveys. I can only check for plausibility from a content point of view, i.e. whether substantial patterns of task change accord with or contradict existing literature.

Figure 6 in the "Appendix" therefore displays box plots of the more robust variety of measurement used from 1973 to 2011. From the beginning of the 1970s until the mid1980s, we observe a decreasing variety of tasks among the occupations which then started to increase again. Whereas the distributions of tasks within occupations in 1996 is comparable to the distribution in 1973, we observe a wider set of tasks within occupations in the new century. This development corresponds with the observations made in the vocational education and training sector during this time. Here, Thelen and Busemeyer (2012), also observe a specialization in training curricula until the 1980s and then a generalization process from this time onwards. However, most observations on task changes over time in the relevant literature concentrate on the task-technology relationship. In the following section,

\footnotetext{
12 The highest uniqueness can be found for "bookkeepers" $(0.7)$ and "data entry clerks" $(0.71)$, the most common set of tasks for "other machine installers" (0.96) and "occupations in cutting metal forming processes" (0.95).

13 Occupations with a narrow set of tasks are "music teachers" (0.04), "primary and secondary school teachers" (0.06) or "medical doctors" (0.08). A wide set of tasks can be found among "security inspectors, health protection occupations" (0.87) or "railway operation personnel, other vehicle operation staff" $(0.85)$.
} 
I will suggest an alternative theoretical view to the task frame by ALM and discuss this relationship in more detail below.

\section{Task and technology}

As stated in the introduction, one of the research interests in tasks is that their observation should help to arrive at a better understanding of the relationship between capital input and labor demand. ALM were the first to provide a theoretical framework that explained the demand for labor due to the technological interventions during the micro-electronic revolution. Whereas newer data collections on tasks in the workplace aim to follow such a theoretical framework (Matthes et al. 2014; Rohrbach-Schmidt 2019), there exists no information for the period of the micro-electronic revolution (from approximately the 1970s until 2010s) that aimed to collect workplace information in accordance with the ALM scheme. Both the microcensuses and the employment surveys are no exception in this regard, as the task information has mainly been collected to supplement and improve occupational classifications (Rohrbach-Schmidt and Tiemann 2013). However, this does not mean that the harmonized tasks are not suited to describe the technology-task relationship over time. But, instead of forcing non-fitting tasks into an established standard, I propose a modification of the ALM scheme. I therefore begin by discussing the common research practice in classifying tasks (of the employment survey) into the ALM scheme (Sect. 4.1) before moving on to elaborate on the task-technology relationship during the micro-electronic revolution (Sect. 4.2). Subsequently I discuss the task-technology-relationship by employment (Sect. 4.3) and wage changes (Sect. 4.4) over time.

\subsection{Task classification by ALM}

According to research practice, manual routine activities are understood as operating, controlling and equipping machines (Black and Spitz-Oener 2010; Haas et al. 2013; SpitzOener 2006) as well as transporting, storing and delivering (Antonczyk et al. 2009).

Manual non-routine activities are generally repairing and renovating, restoring, operating, accommodating, caring for and healing, securing, protecting, guarding, cleaning, waste disposal and recycling (Antonczyk et al. 2009; Black and Spitz-Oener 2010; Haas et al. 2013; Spitz-Oener 2006). Fedorets (2014) also includes building and installing.

Cognitive routine tasks include calculation, accounting, proofreading, measurement, weighing and quality control (Black and Spitz-Oener 2010; Fedorets 2014; Haas et al. 2013; Spitz-Oener 2006).

Interactive non-routine tasks include negotiating, lobbying, coordinating, organizing, teaching, advising, advertising, entertaining, presenting, employing staff and managing (Antonczyk et al. 2009; Spitz-Oener 2006).

Research, analysis, evaluation and planning, construction, design, application and interpretation of law as well as programming are all listed as analytical non-routine tasks (Antonczyk et al. 2009; Black and Spitz-Oener 2010; Gathmann and Schönberg 2010; Haas et al. 2013; Spitz-Oener 2006). Rohrbach-Schmidt and Tiemann (2013) also classify "organizing, planning/preparing working processes" as analytic.

The classification used in research practice shows on the one hand that the distinctions between the different activities are not always clear in the terminology, because in practice 
the different categories can also be connected (Green 2012). On the other hand, it is apparent that the tasks surveyed within a task bundle in the microcensus can also be classified differently according to the ALM scheme. "Typewriting, calculating, booking" can thus be recorded as a cognitive routine activity, whereas "programming" could be classified as analytical. This means that the relationship has to be reformulated based on the available data, which differs from the information of the DOT that served ALM in formulating their thesis. Instead of describing the characteristic of the tasks exercised in the workplace, I argue that one should focus on the relationship of the task to the technology.

\subsection{The task-technology relationship in the micro-electronic revolution}

Increasing computing power (Moore's Law) and the arrival of multiprocessor systems made it possible to record more and more complex work steps using the new control electronics. Both the entire manufacturing process and pre-processing and post-processing tasks are permeated with electronic data processing elements. The establishment of worldwide communication networks such as the Internet ushered in the age of information (Castells 2010), and this also facilitated new business models such as e-commerce from the 1990s onwards (Gordon 2012). Closer consideration of the innovations made possible by microprocessors reveals that the technological responsiveness of the tasks must be classified according to these electronic and information technology innovations, which emerged in the course of the third industrial revolution. ${ }^{14}$ The harmonized tasks will therefore be sorted according to.

- whether they can be replaced by the corresponding technological innovations;

- whether they are directly related to and contribute or provide information to technological innovations;

- whether they are complementary to technological innovations and use them in such a way as to make the activity carried out more productive, or

- whether they are not affected by the technologies in one of the ways mentioned above and their labor demand thus exists relatively independently of the technological solutions.

The difference between technology-accompanying and technology-complementary work is defined by the way in which the technology is used. In technology-accompanying activities, the human being is understood as an assistant to the machine/computer. They supply the machine/computer with information so that it can create a product or service. In this respect, a technology-accompanying activity is directly linked to the technological innovation and-similar to ALM's argumentation regarding cognitive routine work-is also less in demand as productivity of the corresponding technology increases, because the machine/computer, for example, can carry out even more work steps without a separate, manual flow of information. The activity can thus also be automated by using increasing computing power.

In technology-complementary activities, the human being can also act as an assistant to the machine/computer, but - and this is the decisive criterion-they use the technologically

\footnotetext{
14 The cyber-physical systems of the fourth industrial revolution are excluded from the subsequent argumentation due to a different time reference.
} 
or computer-generated output (also) as an aid for their activity, while the corresponding activity itself cannot be automated. Complementary technological tasks are thus activities that benefit from the increasing productivity of technological innovations, because the technologically induced productivity becomes visible in the output of the corresponding activity without the activity itself being substituted. Below, I classify the harmonized tasks in one of the four defined categories depending on how they relate to technological innovation in the micro-electronic revolution.

Technologically replaceable: Tasks that involve "extraction, manufacturing" decrease drastically over time. Most of the subsumed tasks of this tasks bundle are furthermore classified as manual routine tasks in the relevant literature. From both an empirical and theoretical viewpoint, these activities can therefore be classified as technologically replaceable.

Technology-accompanying: The tasks "setting up/adjusting machines" and "typewriting, calculation etc." can both be classified as technology-accompanying. Both tasks have a clear reference to technological innovations. Whereas "setting up/ adjusting machines" decreases slightly over time, "typewriting, calculating etc." increases until the 1990s, before decreasing again. This supports the thesis that both activities contribute to the efficiency of a technologically produced output. However, the more work steps a machine can perform, the fewer the number of people whose main task consists of controlling a machine will be.

Technology-complementary: The tasks "analyzing, measuring etc.", "scheduling, coordinating etc." and "educating, training etc." all increased slightly in employment share between 1973 and 2011. As well as the analytic and interactive content of these tasks, this indicates - in line with the argumentation of ALM - that these activities profit from technological progress as the gainfully employed use the technological output to be more productive.

Technology neutral: Tasks such as "repairing, mending etc.", "buying, selling etc.", "securing, guarding etc.", "serving, accommodating etc." and "nursing/treating medically or cosmetically" are classified as technology neutral. Whereas the share of "repairing, mending etc." decreases over time, "nursing/treating medically or cosmetically" increases dramatically. It can be assumed that this employment growth of the occupations in question is primarily caused by demographic change (Mills and Blossfeld 2005). The employment shares of the other tasks remain relatively stable. None of these tasks relate directly to computers or machines. They are also not easily technologically replaceable, because it is difficult to program the activities. Nor are they "technology-complementary", since there are no signs that technology introduction particularly increased the demand for those tasks.

\subsection{Task change by technology exposure}

Figure 3 shows the overall development of tasks by technology exposure. We can observe an increasing share of technology-accompanying tasks until the beginning of the 1990s and a decrease in the following years. A closer investigation of the underlying trends enables us to observe that this decrease strongly correlates with the declining share of workers at the medium skill level. The overall strong increase in technology-complementary tasks can also mainly be attributed to a changing skill mix in the workforce, namely the higher share of highly qualified workers. ${ }^{15}$

15 The share of highly skilled workers (ISCED 5a, 6) increases continuously from $7 \%$ in 1976 to $18 \%$ in 2011. 


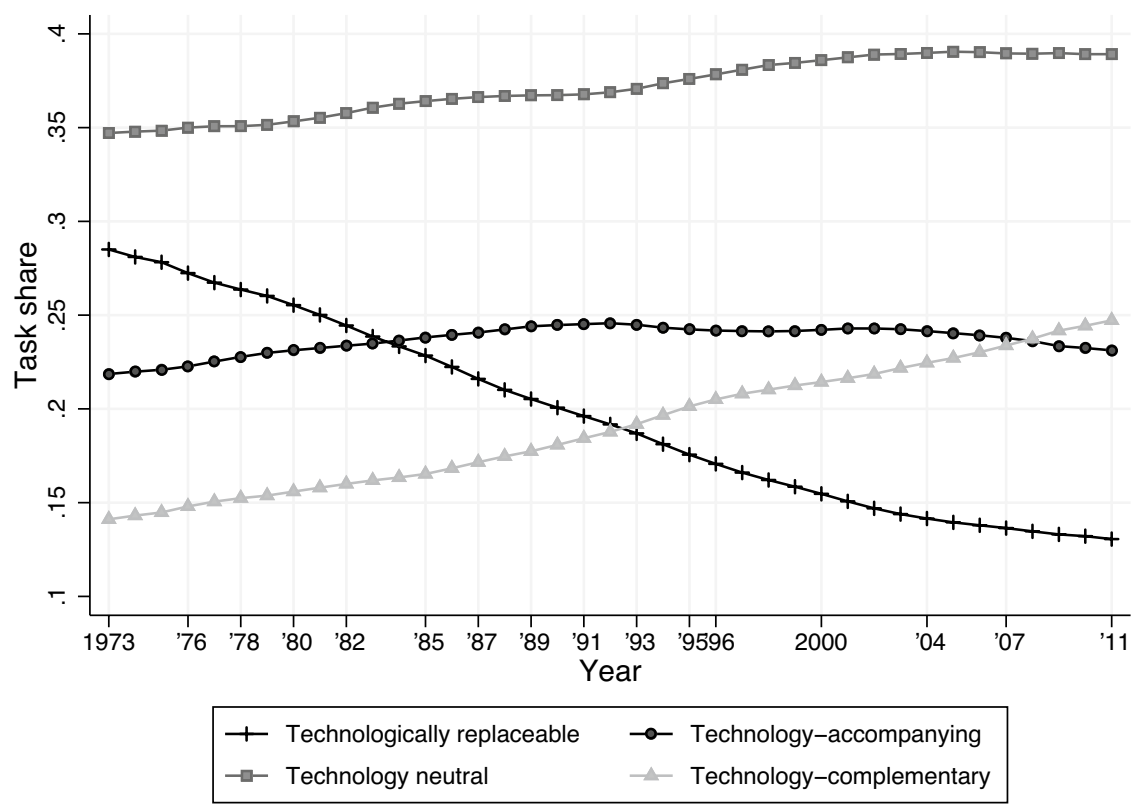

Fig. 3 Task change by technology exposure in Western Germany from 1973 to 2011. Source: Microcensus from the German Federal Statistical Office; own calculations. Values between the survey years interpolated and smoothed with moving averages $(\mathrm{t}-3, \mathrm{t}, \mathrm{t}+3)$

When discussing the impact of new technologies on work, the effects are mostly related to the respective skill levels of the workforce (Acemoglu 1998; Goldin and Katz 1998). Figure 4 therefore shows the development of task shares by technology exposure differentiated by skill level in Western Germany. It is obvious that technologically replaceable tasks ("extraction/manufacturing") are not exercised by highly skilled workers (ISCED 5a, 6), and that the share decreases over time among all three other skill levels. Contrary to the findings of Spitz-Oener (2006), the largest decrease in technologically replaceable tasks is not found at the medium skill level (ISCED 3b,4). It can instead be observed among the low-skilled (ISCED 1, 2, 3a) and among those who have completed higher vocational education (ISCED 5b), whereby the proportion more than halves from 40 and $23 \%$ in 1976 to $19 \%$ and $12 \%$ respectively in 2011.

For the low skilled, we observe the strongest increase in technology neutral tasks of around 15 percentage points from $34 \%$ in 1976 to $49 \%$ in 2011 . This is due to tasks such as "serving, accommodating etc." and corresponds to the findings of Autor and Dorn (2013), who find for the USA that personalized service tasks are locationbound and not easy to substitute. Also, we see that technology-complementary tasks are mostly exercised by highly skilled workers but increase slowly from the beginning of the 1990s among low- and medium-skilled workers, whereas task share among the highly skilled is reduced in favor of technology-accompanying tasks. Among the other 


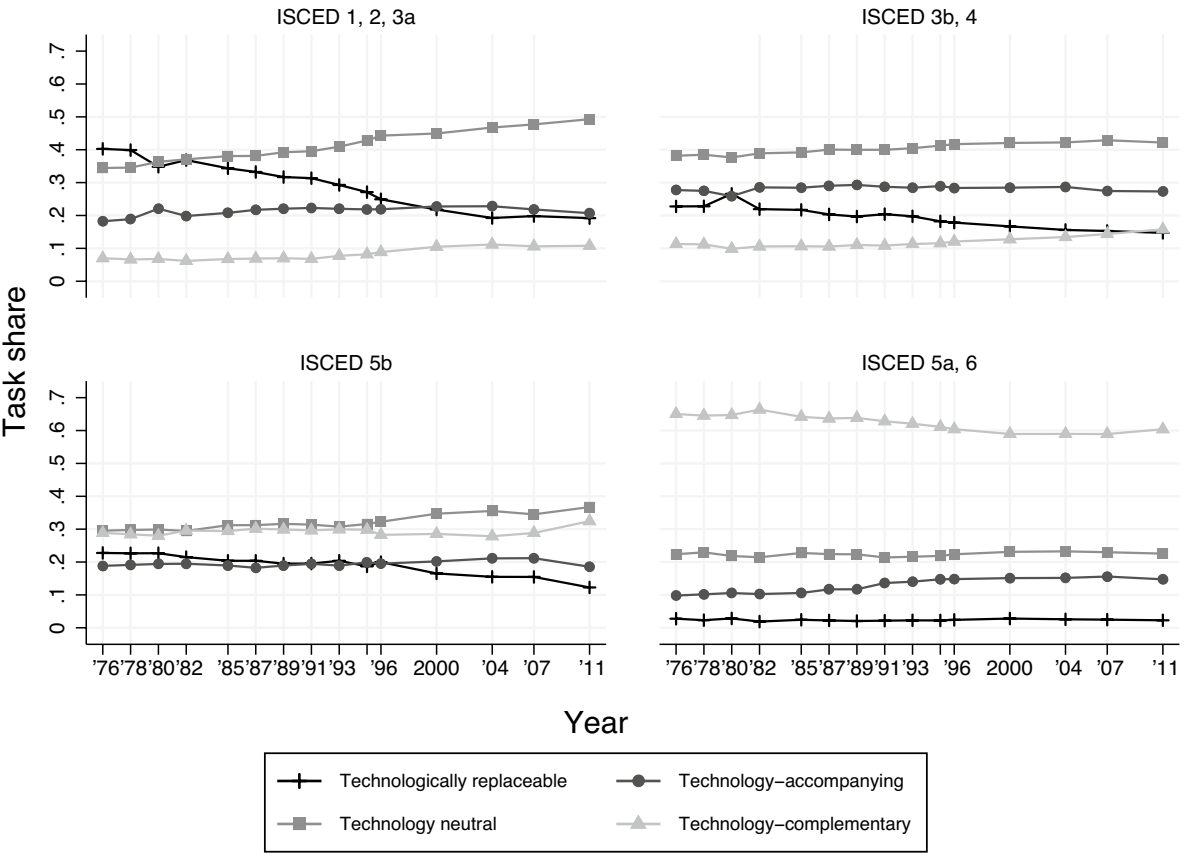

Fig. 4 Task change by technology exposure in Western Germany from 1976 to 2011 differentiated by skill level (ISCED 1997). Source: Microcensus from the German Federal Statistical Office; own calculations

skill levels, the task shares of technology-accompanying tasks remain reasonably stable over time.

\subsection{Task change and wage development}

Due to the harmonization of the occupational groups from different national classifications of occupations, the occupational panel on tasks can be matched to any other data which contains occupational information. I will use this advantage and merge the microcensus panel to a German Occupational Panel (OccPan) ${ }^{16}$ (Hausmann et al. 2015b) that displays the socio-demographic composition of employees within 254 occupational groups (KldB88). This aggregated information at occupational level relies on data for Western Germany for the years 1976 to 2010 from the Sample of Integrated Labor Market Biographies (SIAB). Hausmann et al. (2015a) use it to analyze occupational gender segregation and its consequences. For the analysis on hand, I am mainly interested in the development of the median wage development of an occupation (OccPan) and its possible correlation with the task development at occupational level (microcensus). I therefore restrict the

${ }^{16}$ Data from the OccPan is publicly available from the website of the Institute for Employment Research (IAB): http://doku.iab.de/fdz/reporte/2015/MR_09-15_Daten.zip (13.07.2020). 

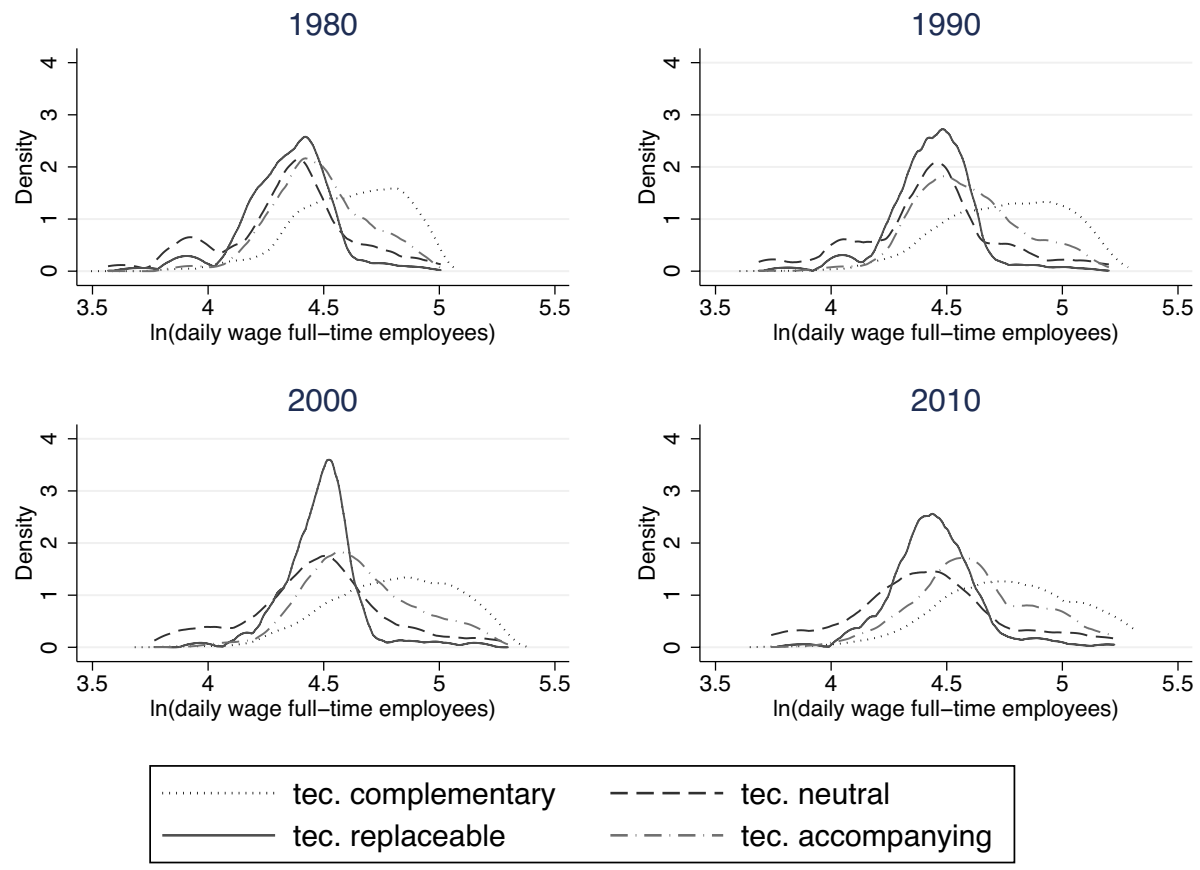

Fig. 5 Kernel-Density-Plots of the wage distribution weighted by task share from 1980 to 2010. Source: Microcensus from the German Federal Statistical Office; own calculations based on 155 occupational groups. Estimation of kernel-density with Epanechnikov kernel function

microcensus survey to blue- and white-collar workers subject to social security contributions. This reduces the sample size of occupations with a larger share of civil servants, self-employed, or helping family members. If fewer than 30 persons remain in an occupation in more than two survey years, I exclude the occupation from the analysis. ${ }^{17}$ It was mostly possible to aggregate the 254 occupational groups in OccPan to the harmonized occupational groups. However, it was also necessary to aggregate some occupations in the task panel to fit some occupational aggregations in OccPan. ${ }^{18}$ In the end, I have 155 occupational groups.

My variable of interest in the OccPan is the median wage of an occupation. Coming from the TBTC-theory, we would not only expect a decrease in employment with technologically replaceable tasks (manual routine), but also relative wage losses compared to technological complementary (information processing) tasks. According to the theory, the wage development of technologically neutral or accompanying tasks could be ambiguous. Whereas the first consists predominantly (but not exclusively) of non-routine manual tasks, the latter principally (but not solely) comprises cognitive routine. This would imply that an

\footnotetext{
17 This concerned the occupations: (286) "clockmakers", (811) "judges, district attorneys", (814) "law enforcement professionals and prison staff", (842) "dentists", (843) "veterinarians", (883) and "other natural scientists and researchers, statisticians and market researchers".

18 With reference to the occupational codes, the following occupations of the KldB88g have been aggregated: $(11+31),(71+81+141),(250+283),(391+392),(544+545+546),(281+686),(742+743)$, $(771+772),(781+783),(912+913),(934+936)$.
} 
Table 2 Fixed-Effects-Regression of task-measures on the logarithmic median daily wage of full-time employees subject to social security (1976-2010). Source: Microcensus from the German Federal Statistical Office and OccPan

\begin{tabular}{|c|c|c|c|}
\hline & M1 & M2 & M3 \\
\hline \multicolumn{4}{|c|}{ Task-technology-relationship (ref.: share of technologically replaceable tasks) } \\
\hline \multirow[t]{2}{*}{ Technology-accompanying } & 0.002 & 0.002 & 0.003 \\
\hline & $(0.000)^{* *}$ & $(0.000)^{* *}$ & $(0.000)^{* *}$ \\
\hline \multirow[t]{2}{*}{ Technology neutral } & 0.002 & 0.002 & 0.003 \\
\hline & $(0.000)^{* *}$ & $(0.000)^{* *}$ & $(0.000)^{* *}$ \\
\hline \multirow[t]{2}{*}{ Technology-complementary } & 0.002 & 0.003 & 0.002 \\
\hline & $(0.000)^{* *}$ & $(0.000)^{* *}$ & $(0.000)^{* *}$ \\
\hline \multirow[t]{2}{*}{ Commonness of the task set } & & 0.000 & -0.001 \\
\hline & & $(0.001)$ & $(0.001)$ \\
\hline \multirow[t]{2}{*}{ Width of the task set (variety) } & & -0.001 & -0.002 \\
\hline & & $(0.000)^{* *}$ & $(0.000)^{* *}$ \\
\hline \multicolumn{4}{|c|}{$\begin{array}{l}\text { Educational composition (ref.: share of vocational education without an upper secondary school leaving } \\
\text { certificate) }\end{array}$} \\
\hline \multirow[t]{2}{*}{ Unskilled } & & & -0.002 \\
\hline & & & $(0.000)^{* *}$ \\
\hline \multirow[t]{2}{*}{ With an upper secondary school leaving certificate } & & & 0.001 \\
\hline & & & $(0.000)^{* *}$ \\
\hline \multirow[t]{2}{*}{ University (of Applied Sciences) degree } & & & 0.006 \\
\hline & & & $(0.000)^{* *}$ \\
\hline \multirow[t]{2}{*}{ Year } & 0.006 & 0.006 & 0.004 \\
\hline & $(0.000)^{* *}$ & $(0.000)^{* * *}$ & $(0.000)^{* *}$ \\
\hline \multirow[t]{2}{*}{ Constant } & -7.618 & -7.725 & -3.772 \\
\hline & $(0.191)^{* *}$ & $(0.201)^{* *}$ & $(0.384)^{* *}$ \\
\hline$R^{2}$ & 0.48 & 0.49 & 0.52 \\
\hline $\mathrm{N}$ & 5425 & 5425 & 4424 \\
\hline
\end{tabular}

Only Western Germany. 155 occupational groups and 35 years. Own calculations. Sample size in M4 is less due to missing values in the educational composition in some occupations and years. $* p<0.05 ; * * p<0.01$

increase in technologically neutral tasks (as compared to technologically replaceable tasks) within an occupation could be associated with a relative wage increase.

The OccPan includes daily wages rather than hourly wages. As the former may differ by the number of hours worked a day, I reduce the heterogeneity by analyzing only the median of the logarithmic daily wages of full-time employed persons. Figure 5 shows kernel-density plots of the logarithmic daily wages of full-time employed persons weighted by the share of tasks in 1980, 1990, 2000 and 2010. It shows that technologycomplementary task profiles are found at the higher end of the wage distribution in all years. Furthermore, we see that technology-accompanying tasks have increased at the higher end of the wage distribution from 1980 to 2010. The wage distribution of technologically replaceable tasks is steeper than that for neutral tasks in all years. However, the average occupational wage for these tasks seems similar.

Table 2 presents the results of three fixed-effect panel regressions on an occupational basis for the period from 1976 to 2010. Model M1 only concentrates on the 
task-technology-relationship. Here, the effects correspond with the theoretical expectation. Compared to technologically replaceable tasks, the median wage of the occupation increases by $0.2 \%$ if the share of technology-accompanying, neutral and complementary tasks increases by $1 \%$. There is no significant difference between the shares of technologically neutral or accompanying tasks. However, an increase in complementary tasks compared to all other tasks correlates significantly with a wage increase within the occupation.

Model M2 additionally controls for the specificity of the occupations. The commonness measure (see Sect. 3.2) has no effect on wage changes within occupations. However, in line with theoretical expectations of Rotolo and McPherson (2001), we see a significant decrease in the occupations specific wage if the width of the occupational tasks increases (see also Eggenberger et al. (2018)). If controlled for this specificity, we see a stronger wage increase with increasing technology-complementary tasks compared to technologically replaceable tasks. This effect even increases if I control for the educational composition of the occupation (M4). ${ }^{19}$ Here, we observe a clear hierarchical relationship. The higher the increase of qualified workers within an occupation, the higher the occupational wage growth will be. The higher share of technology-complementary task profiles in premium wage occupations and the increasing share of technology-accompanying tasks in premium wage occupations (Fig. 5) from 1980 until 2010 can therefore also be explained by tasks and qualification changes within an occupational group. ${ }^{20}$

\section{Conclusion}

Research in TBTC, human capital theory and institutional economic and sociology has shown an increasing interest in task change between and within occupations (see Sect. 1). However, data sources that illustrate this change between the 1970s until 2010 are rare. This paper thus introduced the German microcensus, the largest household survey in Germany, as an additional data source to monitor task change in the time stated. Since 1973, it has been possible to gain an insight into the activity predominantly exercised by gainfully employed persons in the SUFs of the German microcensus. The large sample size of occupational incumbents permits a representative distribution of the most relevant tasks exercised in an occupation for each survey year. However, this information has never been used to research the changing demand for tasks. This paper thus pursued the objectives of harmonizing the task information at occupational level, of making it available to academic research (https://doi.org/10.7802/2126) and of showing its research potential.

After describing the harmonization process of the tasks (Sect. 2), I illustrated the development over time (Sect. 3.1) and checked the robustness of the results in the light of alternative assumptions (Sect. 3.2). It was found that the transition key created is only marginally sensitive with regard to the order and number of the variables used for the

\footnotetext{
19 OccPan contains a few sociodemographic characteristics of an occupation, such as the share of female workers or part-time workers. However, because some cells had to be marked as missing due to anonymization, the additional consideration of these variables reduces the sample size. This is also the case with the educational composition.

${ }^{20}$ If we classify occupations according to their predominant task (e.g. technologically replaceable tasks), a growth curve analysis shows us no significantly different wage growth by occupational cluster. Therefore, different wage developments can rather be explained with a changing mix of tasks within the occupations.
} 
transformation. However, it is important to consider the amount of hours worked, as this influences the results and is significant because full-time employees apparently exercise predominant activities, which are different to those carried out by part-time employees in the same occupation. Furthermore, it turned out that the commonness of tasks of an occupation (according to Stuth (2017)) depends strongly on the amount of tasks measured. Variety, which shows the breadth of the occupational task set, is, however, not affected by the harmonization process. Here, we can observe a decreasing variety of tasks among the occupations from 1973 onwards, which then started to increase again in the mid-1980s.

As no external benchmark exists with which the task changes of the microcensus can be compared, I checked in Sect. 4 whether the apparent patterns of task change accord with or contradict existing literature. I related the harmonized tasks to the technological innovations in the third industrial (micro-electronic) revolution. Common classifications of tasks according to the ALM scheme cannot be used, as the harmonized tasks do not measure the task according to this scheme (Sect. 4.1). I therefore addressed the relationship between the technological innovations in the micro-electronic revolution and the tasks directly (Sect. 4.2). I differentiated between tasks that can be replaced by technological innovations in this period, technology-accompanying tasks that contribute or provide information to computers and technology-complementary tasks that benefit from technological output. The description in Sect. 4.3 shows that technology neutral activities exist relatively independently of technological solutions. Technologically replaceable tasks were hardly carried out by highly skilled workers and decreased among all skill levels over time, whereas the share of technology neutral tasks increased among the low- and medium-skilled. Additionally, we observe a continuous increase in technology-complementary tasks, whereas technology-accompanying tasks increase until the beginning of the 1990s and decrease in the years after. These patterns are in line with the common theoretical expectations.

Due to the harmonization of the national occupational codes, the task panel can be matched to any other data sources, which contain occupational information according to the KldB1975, KldB1988 or KldB1992. To show the relationship between within-occupational task changes and wages, I matched the task panel to OccPan (Hausmann et al. 2015b), a publicly available panel on the sociodemographic composition of occupations (Sect. 4.4). The weighted wage distribution by task shares shows that technology-complementary task profiles are often found in premium wage occupations in all years and that the share of technology-accompanying tasks increased in premium wage occupations from 1980 until 2010. Technologically replaceable and neutral task profiles tend to be at the end of the wage distribution. A fixed-effect-panel regression reveals-in line with the theoretical expectations - that a decreasing share of technological replaceable tasks in an occupation is accompanied by an increase in the median daily wage at occupational level, especially if the share of technology-complementary tasks (or technology-accompanying) increases instead. The widening of the task set of an occupation correlates significantly with a wage decrease. The less specific the task profile is, the more people can do the job and the higher the supply of labor for the occupation will be.

This paper aimed to provide a task panel on occupational level for science and to show the associated potential of the newly created data source. The displayed results are only descriptive. To obtain further explanations, e.g. regarding wage development, the task panel should be matched to other data sources, such as individual panel studies. The analysis potential is, however, not restricted to the indicators shown. Especially in the research of human capital theory, there are further measurements (such as Euclidian distance or angular separation) that can be calculated to demonstrate the transferability of tasks (or skills that enable the performance of tasks). As shown, the 
harmonized tasks are not exclusive to a specific occupation. Following the skill-weight approach of Lazear (2009), it can be argued that the specificity of an occupation arises due to the different composition of the tasks in an occupation (Eggenberger et al. 2018; Geel and Backes-Gellner 2011). To obtain not only horizontal information on the average distribution of tasks in an occupation, one could for example additionally use the average schooling years of the occupation incumbents to display the usual educational investment to exercise an occupation (Nedelkoska et al. 2015). This vertical component would allow a further pronunciation of differences in task profiles with similar predominant activities (e.g. "nurses" and "medical doctors") (Ormiston 2014).

Finally, it must be noted that task change is nevertheless likely to be underestimated in the task panel due to the question of predominant activity. The question of how many activities are exercised is not surveyed. This means that the task information of the microcensus might not be the right data choice if the complexity of occupational tasks is to be investigated.

\section{Appendix}

See Tables 3, 4, 5, 6 and 7, Fig. 6.

Table 3 Harmonized information on latest/highest occupational degree in the microcensus from 1976 to 2011

\begin{tabular}{ll}
\hline Occupational degree & ISCED category \\
\hline No vocational qualification & $1,2,3 \mathrm{a}$ \\
Vocational training & $3 \mathrm{~b}, 4$ \\
Master craftsman/technician degree & $5 \mathrm{~b}$ \\
Degree from a university (of applied sciences) & $5 \mathrm{a}, 6$ \\
\hline
\end{tabular}




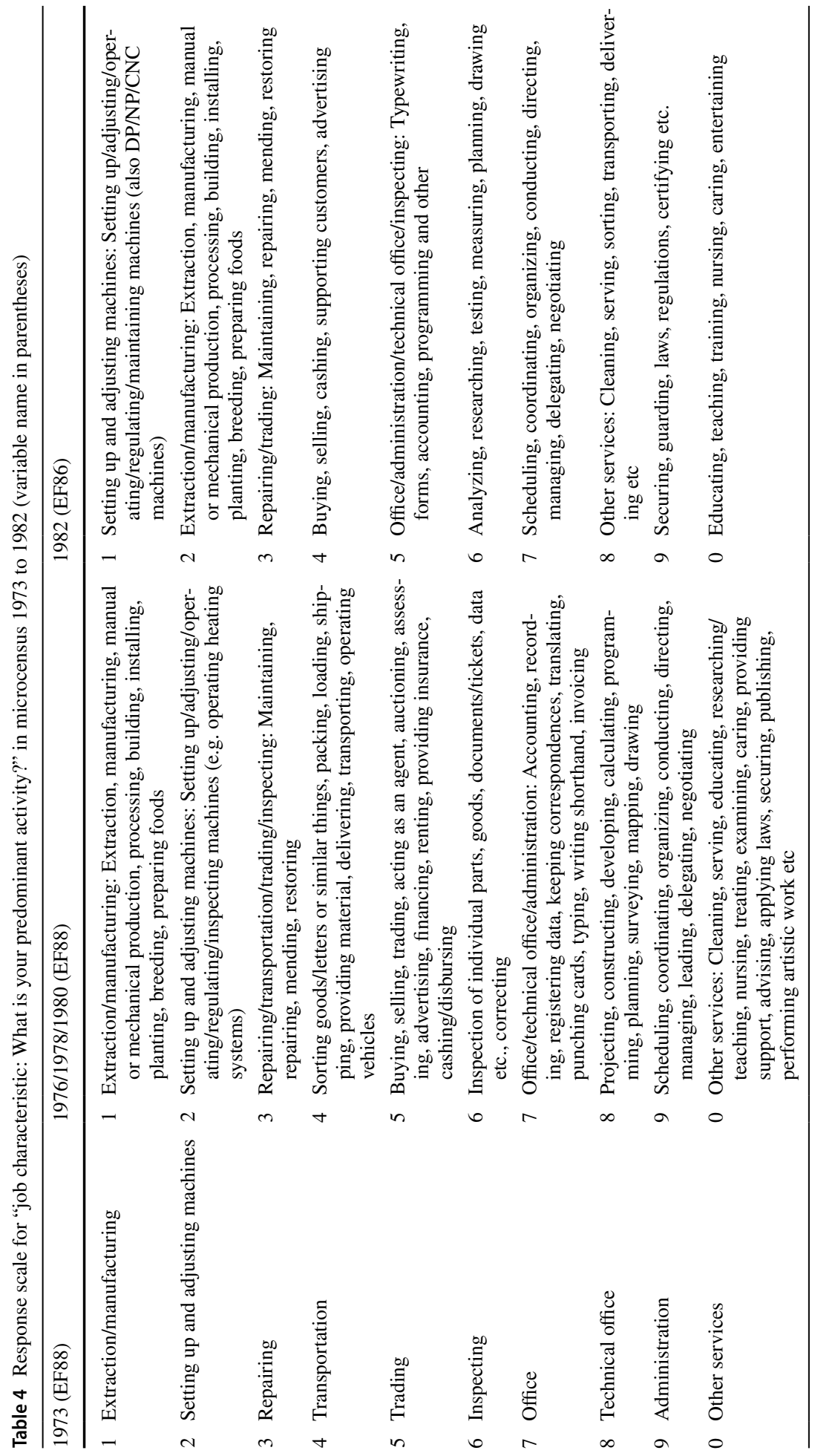


Table 5 Response scale for "Activity predominantly exercised-additional entry A to D" microcensus 1973, 1976, 1978, 1980 (Variable EF89)

\section{A. Task focus}

11 Planting, growing, harvesting, fishing, lumbering, keeping animals

12 Extracting, stone cutting

13 Mechanically producing and processing (e.g. rotating, punching, printing, spinning, roasting, baking, frosting etc.)

14 Manually producing and processing; preparing foods

15 Installing/assembling parts

16 Building/finishing

17 Giving orders/instructing other people when producing/processing/installing etc.

20 Setting up/adjusting/operating/regulating/inspecting machines

\section{B. Object of work}

30 Foods, beverages, tobacco

31 Textiles, knitted fabric, clothes, leather

32 Metal goods (cutlery, jewelry etc.), metal and plastic component parts

33 Machines/electrical equipment, measurement instruments, clocks

34 Vehicles, means of transportation

35 Piping/buildings/facilities/traffic facilities

36 Other types of products/raw materials

37 Monetary values/real estate

38 Data, information, documents, art, travel etc.

39 No object but people

C. Main field of functions/operational area

41 Procurement, purchasing, storage

42 Research and development, construction, project planning

43 Job scheduling, production, inspection, revision

44 Sales, advertising, public relations

45 Accounting, budgeting, financing, statistics

46 Data processing (ADP/EDP)

47 Human resources, social work, training

48 Appraisal of applications, assisting secretariat, documentation, clerical services

49 Organizing, coordinating, executive board, management

\section{Main services}

51 Cleaning, washing, ironing, re-coloring

52 Supplying kitchens, residential homes or private households, serving customers, accommodating

53 Researching, teaching, training, educating, caring

54 Examining, treating medically or cosmetically, nursing

55 Maintaining order, securing

56 Interpreting law and order, certifying

57 Advising (especially job, education and life coaches)

58 Publishing, artistic work

59 Miscellaneous (also training for a job) 


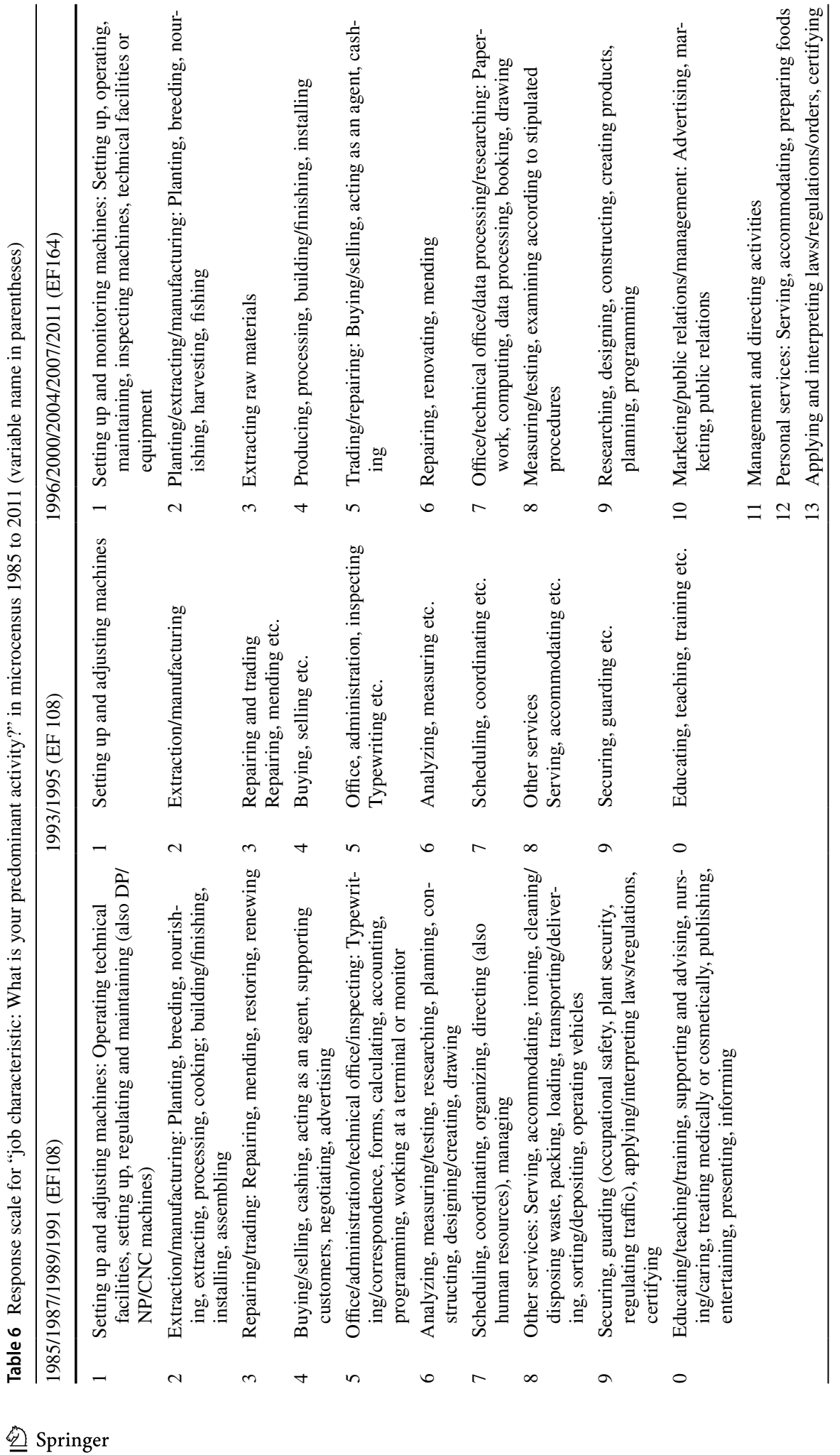




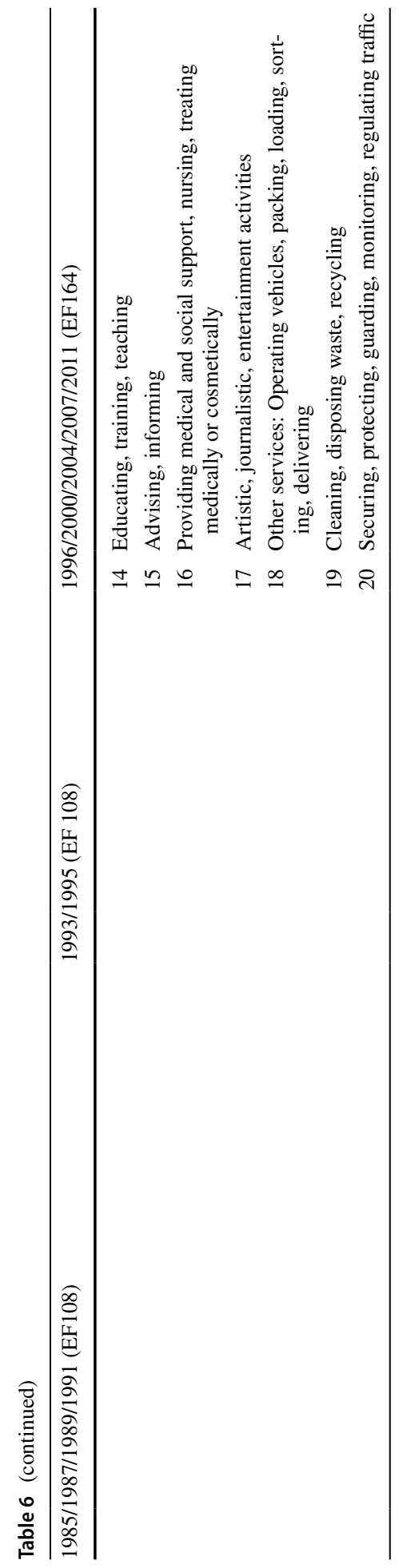




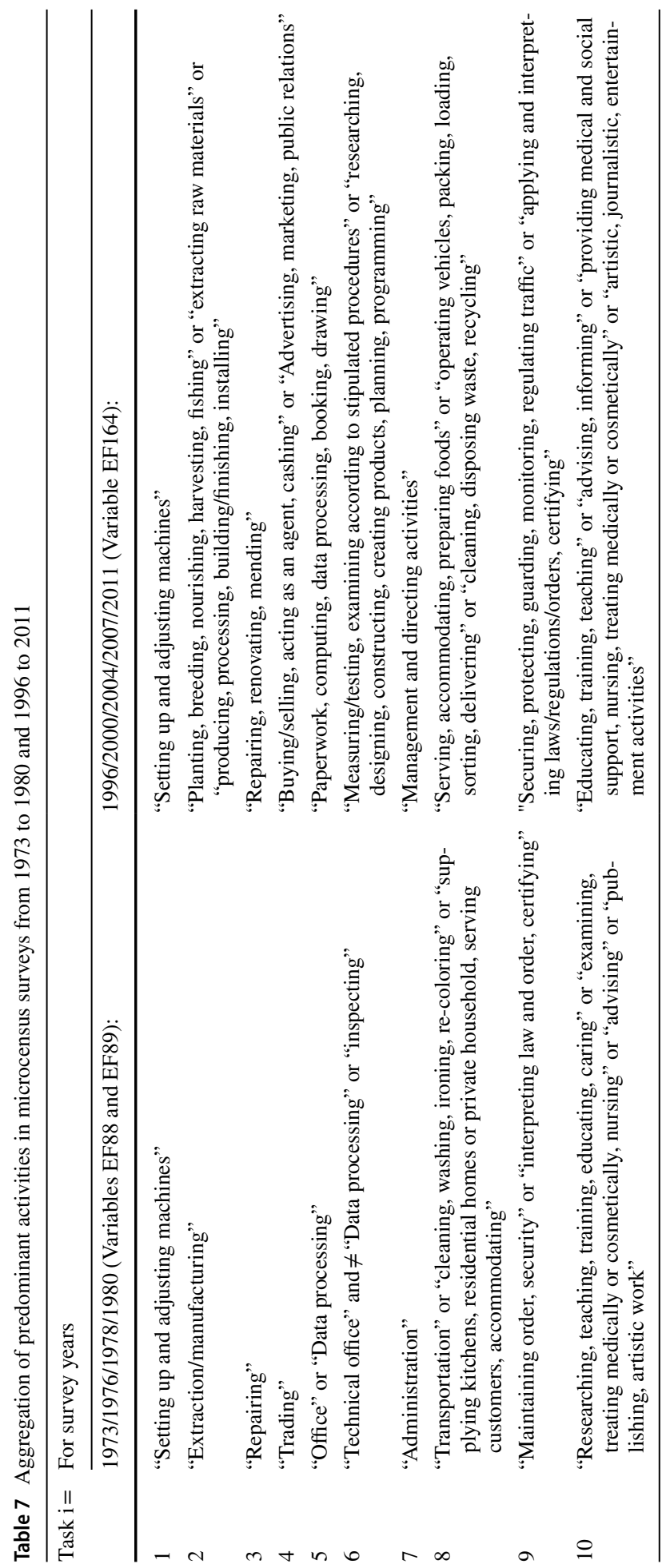




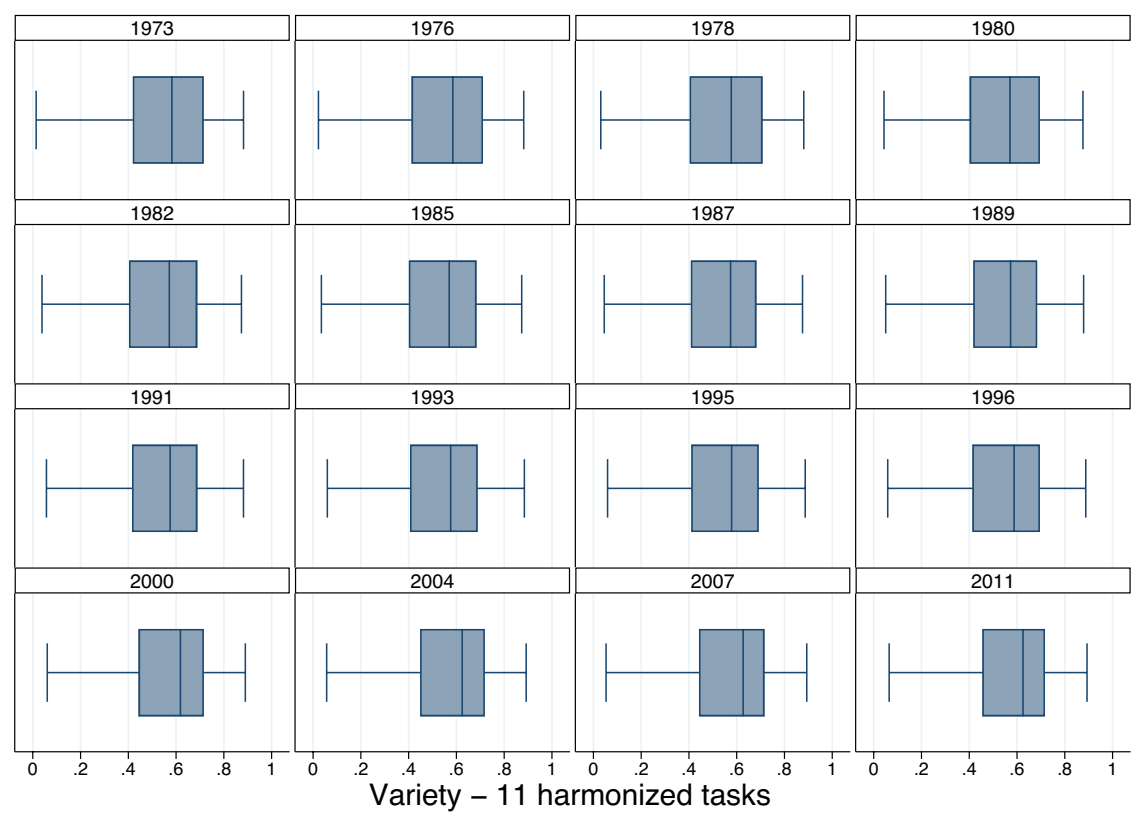

Fig. 6 Box plots of variety of occupations between 1973 and 2011 according to 11 harmonized task categories. Source: Microcensus from the German Federal Statistical Office; own calculations. Calculations of the variety are based on 176 harmonized occupational groups. The box plots exclude outliers

Funding Open Access funding enabled and organized by Projekt DEAL. Not applicable.

Data availability The task panel on occupational level can be accessed on https://doi.org/10.7802/2126.

Code availability The Stata code for this analysis can be obtained from the author.

\section{Declarations}

Conflict of interest The author declares that there is no conflict of interest.

Open Access This article is licensed under a Creative Commons Attribution 4.0 International License, which permits use, sharing, adaptation, distribution and reproduction in any medium or format, as long as you give appropriate credit to the original author(s) and the source, provide a link to the Creative Commons licence, and indicate if changes were made. The images or other third party material in this article are included in the article's Creative Commons licence, unless indicated otherwise in a credit line to the material. If material is not included in the article's Creative Commons licence and your intended use is not permitted by statutory regulation or exceeds the permitted use, you will need to obtain permission directly from the copyright holder. To view a copy of this licence, visit http://creativecommons.org/licenses/by/4.0/. 


\section{References}

Acemoglu, D.: Why do new technologies complement skills? Directed Technical Change and Wage Inequality. Q.j. Econ. 113, 1055-1089 (1998)

Antonczyk, D., Fitzenberger, B., Leuschner, U.: Can a Task-Based Approach Explain the Recent Changes in the German Wage Structure? IZA Discussion-Paper No. 4050, (2009)

Autor, D.H., Dorn, D.: The Growth of Low Skill Service Jobs and the Polarization of the U.S. Labor Market. Am Econ Rev. 103, 1553-1597 (2013)

Autor, D.H., Handel, M.J.: Putting tasks to the test: Human capital, job tasks and wages. J. Labor Econ. 31, S59S96 (2013)

Autor, D.H., Levy, F., Murnane, R.J.: The skill content of recent technological change: an American exploration. Q. j. Econ. 4, 1279-1333 (2003)

Becker, G.S.: Investment in human capital. Theor. Anal. j. Political Econ. 70, 9-49 (1962)

Black, S.E., Spitz-Oener, A.: Explaining women's success: technological change and the skill contetnt of women's work. Rev. Econ. Stat. 92, 187-194 (2010)

Castells, M.: The rise of the network society, vol. 1, 2nd edn. Wiley-Blackwell, West Sussex (2010)

Chennells, L., Reenen, J.V.: Has Technology Hurt Less Skilled Workers? An Econometric Survey of the Effects on the Structure of Pay and Jobs. The Institute For Fiscal Studies. Working Paper Series No. W99/27, (1999)

Christoph, B., Matthes, B., Ebner, C.: Occupation-Based Measures — An Overview and Discussion. Kölner Zeitschrift für Soziologie und Sozialpsychologie Special Edition "Berufe und Soziale Ungleichheit", pp. 1-38 (2020).https://doi.org/10.1007/s11577-020-00673-4

Dengler, K., Matthes, B.: The impacts of digital transformation on the labour market: Substitution potentials of occupations in Germany. Technol. Forecast. Soc. Change 137, 304-316 (2018)

Dengler, K., Matthes, B., Paulus, W.: Occupational Tasks in the German Labour Market. An Alternative Measurement on the Basis of an Expert Database. FDZ-Methodenreport 12/2014. Institut für Arbeitsmarkt- und Berufsforschung., Nürnberg (2014)

Dengler, K., Stops, M., Vicari, B.: Occupation-specific matching efficiency. IAB-Discussion Paper 16/2016, (2016)

Eggenberger, C., Rinawi, M., Backes-Gellner, U.: Occupational specificity: a new measurement based on training curricula and its effect on labor market outcomes. Labour Econ. 51, 97-107 (2018)

Fedorets, A.: Closing the Gender Pay Gap and Individual Task Profiles: Women s Advantages from Technological Progress. Beiträge zur Jahrestagung des Vereins für Socialpolitik 2014: Evidenzbasierte Wirtschaftspolitik-Session: Gender Issues, No. G03-V4, (2014)

Gathmann, C., Schönberg, U.: How general is human capital? A task-based approach. J. Labor Econ. 28, 1-49 (2010)

Geel, R., Backes-Gellner, U.: Occupational mobility within and between skill clusters: An empirical anaysis based on the skill-weights approach empirical research in vocational. Educ. Train. 3, 21-38 (2011)

Goldin, C., Katz, L.F.: The origins of technology-skill complementarity. Q. j. Econ. 113, 693-732 (1998)

Gordon, R.J.: Is the US economic growth over? Faltering innovation confronts the six headwinds. NBER Working Paper Series No. 18315, (2012)

Green, F.: Employee involment, technology and evolution in job skills: a task-based analysis. Ind. Labor Relat. Rev. 65, 36-67 (2012)

Grønning, M., Kriesi, I., Sacchi, S.: Skill Specificity of Upper-Secondary Training Occupations and the Gender Pay Gap. Kölner Zeitschrift für Soziologie und Sozialpsychologie Special Edition "Berufe und Soziale Ungleichheit", pp. 1-25 (2020).https://doi.org/10.1007/s11577-020-00678-Z

Haas, A., Lucht, M., Schanne, N.: Why to employ both migrants and natives? A study on task-specific substitutability. J. Labour Mark. Res. 46, 201-214 (2013)

Hausmann, A.-C., Kleinert, C., Leuze, K.: Entwertung von Frauenberufen oder Entwertung von Frauen im Beruf? Eine Längsschnittanalyse Zum Zusammenhang Von Beruflicher Geschlechtersegregation Kölner Zeitschrift Für Soziologie Und Sozialpsychologie 67, 217-242 (2015a)

Hausmann, A.-C., Zucco, A., Kleinert, C.: Berufspanel für Westdeutschland 1976-2010 (OccPan). Dokumentation zur Erstellung und Anonymisierung. FDZ-Methodenreport Bundesagentur für Arbeit 09/2015, (2015b)

Kambourov, G., Manovskii, I.: Occupational specifity of human capital. Int. Econ. Rev. 50, 63-115 (2009)

Lazear, E.P.: Firm-specific human capital: a skill-weights approach. J. Political Econ. 117, 914-940 (2009)

Lengerer, A., Schroedter, J.H., Boehle, M., Wolf, C.: The GESIS Microcensus-Trendfile-a new database for the study of social change. Schmollers Jahr. 132, 419-432 (2012)

Matthes, B., Christoph, B., Janik, F., Ruland, M.: Collecting information on job tasks-an instrument to measure tasks required at the workplace in a multi-topic survey. J. Labour Mark. Res. 47, 273-297 (2014) 
Mills, M., Blossfeld, H.-P.: Globalization, uncertainty and youth in society. The losers in a globalizing world. In: Blossfeld, H.-P., Klijzing, E., Mills, M., Kurz, K. (eds.), pp 1-24. Routledge, Abingdon (2005)

Nedelkoska, L., Neffke, F., Wiederhold, S.: Skill Mismatch and the Costs of Job Displacement. CESifo Area Conferences 2015, (2015)

Ormiston, R.: Worker displacement and occupation-specific human capital. Work. Occup. 41, 350-384 (2014)

Rohrbach-Schmidt, D.: Putting tasks to the test: the case of Germany. Soc. Incl. 7, 122-135 (2019)

Rohrbach-Schmidt, D., Tiemann, M.: Changes in workplace in Germany-evaluating skill and task measures. J. Labour Mark. Res. 46, 215-237 (2013)

Rotolo, T., McPherson, J.M.: The sytem of occupations: modeling occupations in sociodemographic space. Soc. Forces 79, 1095-1130 (2001)

Schimpl-Neimanns, B.: Mikrodaten-tools: Umsetzung der Berufsklassifikation von Blossfeld auf die Mikrozensen 1973-1998. (2003)

Spitz-Oener, A.: Technical change job tasks, and rising educational demands: looking outside the wage structure. J. Labour Econ. 24, 235-270 (2006)

Stuth, S.: Closing in on Closure. Occupational Closure and Temporary Employment in Germany. Nomos Verlagsgesellschaft/edition sigma, Baden-Baden (2017)

Thelen, K., Busemeyer, M.R.: Institutional change in German vocational training: from collectivism toward segmentalism. In: Busemeyer, M.R., Trampusch, C. (eds.) the Political Economy of Collective Skill Formation, pp. 68-100. Oxford University Press, Oxford (2012)

Tiemann, M., Schade, H.-J., Helmrich, R., Hall, A., Braun, U., Bott, P.: Berufsfeld-Definitionen des BIBB auf Basis der KldB1992. Wissenschaftliche Diskussionspapiere, vol. 105, 2 edn. Bundesinstitut für Berufsbildung, Bonn (2008)

Publisher's Note Springer Nature remains neutral with regard to jurisdictional claims in published maps and institutional affiliations. 